Competitive Positioning in Markets with Nonuniform Preferences

Author(s): Asim Ansari, Nicholas Economides and Avijit Ghosh

Reviewed work(s):

Source: Marketing Science, Vol. 13, No. 3 (Summer, 1994), pp. 248-273

Published by: INFORMS

Stable URL: http://www.jstor.org/stable/183676

Accessed: 14/10/2012 21:25

Your use of the JSTOR archive indicates your acceptance of the Terms \& Conditions of Use, available at http://www.jstor.org/page/info/about/policies/terms.jsp

JSTOR is a not-for-profit service that helps scholars, researchers, and students discover, use, and build upon a wide range of content in a trusted digital archive. We use information technology and tools to increase productivity and facilitate new forms of scholarship. For more information about JSTOR, please contact support@jstor.org. 


\title{
COMPETITIVE POSITIONING IN MARKETS WITH NONUNIFORM PREFERENCES
}

\author{
ASIM ANSARI, NICHOLAS ECONOMIDES, AND AVIJIT GHOSH \\ University of British Columbia \\ New York University \\ New York University
}

\begin{abstract}
We investigate the nature of competitive equilibrium for brands competing in a multi-attribute product space when consumer preferences for product attributes follow nonuniform distributions. We establish subgame-perfect equilibria in a two-stage game, where firms choose positions in the first stage and prices in the second stage. Two types of entry scenarios are investigated. In the first, the number of brands is given exogenously, and all of them choose positions simultaneously. In the second scenario, firms enter in sequence, and the early entrants can choose strategies to deter the entry of later entrants. We find the equilibria for two, three, and four brands for consumer preferences that follow a beta distribution. Nonuniform distributions result in equilibrium configurations that are substantially different from those obtained for uniform consumer distributions. In the two brands case, for sufficiently concentrated distributions we find asymmetric position equilibria with one firm at the corner of the market and one firm at an interior position. In the case of three brands, for sufficiently concentrated preferences we find symmetric equilibria that do not yield maximal differentiation. We also establish an equilibrium for the case of four competing brands. In addition we characterize entry deterring positioning strategies and examine how they vary with the distribution of consumer preferences.

(Competitive Strategy; Product Policy; Game Theory)
\end{abstract}

\section{Introduction}

Positioning, the place a product occupies in a given market, is the foundation of marketing strategy. A brand's position differentiates it from its competitors on attributes considered important by target customers and gives it a distinctive identity in their minds. As Wind (1990, 387) puts it, positioning "is the product's reason for being, the reason why consumers buy it." In the marketing literature it is now well accepted that a brand's position is an important determinant of its competitive strength and that the brand's physical design and marketing strategy must be consistent with its intended position (Urban and Hauser 1980, Kotler 1990, Wind 1990). Firms position their brands by selecting the optimal mix of tangible and intangible product attributes as well as prices. The distribution of consumer preferences and the existing or anticipated positions of competitive brands are both critical inputs to the positioning decision. Product positioning, therefore, requires a synthesis of consumer and competitor analyses (Shapiro, Dolan and Quelch 1985). 
Given the importance of the positioning decision, a number of analytical frameworks have been proposed for optimally positioning brands in competitive markets. Hauser and Shugan's ( 1983 ) "Defender" model, for example, investigates the optimal defensive response to a new entrant. Hauser (1988) extends the basic Defender framework and determines the competitive position and price equilibrium among brands competing in a multi-attribute space. Price and position equilibria are also investigated by Moorthy (1988), Kumar and Sudarshan (1988), and Carpenter (1989), among others. Moorthy (1988) examines duopoly firms competing on price and a single quality attribute. Carpenter (1989) looks at a two-attribute model in which consumers have ideal points that describe their most preferred levels of each attribute.

Ever since the publication of Hotelling's (1929) paper, competitive positioning issues have been studied by economists. The Hotelling model sought to determine the optimal location of retail firms in a linear market with uniform distribution of consumers. Hotelling argued that two sellers in this market would both cluster at the center to maximize their respective market shares. This is the principle of minimum differentiation. D'Aspremont, Gabszewicz, and Thisse (1979) show that minimum differentiation is not an equilibrium in the Hotelling model if one allows for the possibility that firms can undercut their competitor's price to capture the entire market. They modify Hotelling's model to ensure price equilibrium at all product positions and show that firms differentiate maximally in equilibrium. The models of Shaked and Sutton (1982), Economides (1984, 1986b) and Hauser (1988), among others, too, suggest differentiation rather than clustering of brands.

In a competitive market, the optimal product positions are determined by the interplay of two opposing influences. The price rivalry between closely positioned brands provides incentives for differentiation. Greater differentiation reduces the intensity of price rivalry and increases profits for all firms. This motivation is counteracted, however, by the tendency of firms to cluster around the majority customer preference. This exerts an agglomerative influence as firms want to position where consumers are. In most models that assume uniform consumer preferences, the strategic effect due to price competition dominates the agglomerative influence and yields maximal differentiation of brands as the equilibrium outcome.

Starting with Hotelling, most models of spatial competition, whether in marketing or economics, have assumed a uniform distribution for consumers preferences. Models in spatial economics, for example, assume that the density of consumers is the same everywhere in the market. Brand-positioning models deal with consumer preferences rather than their physical location, but the uniformity assumption persists. They typically assume that consumer preferences for product attributes are distributed uniformly in the attribute space. The uniformity assumption is convenient for deriving analytical results, but it may not be highly satisfactory in representing actual consumer distributions in many markets. Consider, for example, the market for symbolic algebra computer software. Products in this market can be characterized by their position along two attributes: 1) processing speed, and 2) flexibility (characterized by the number of built-in functions and applications). The distribution of consumer preferences in this market is unlikely to be uniform (i.e., equal number of consumers preferring each possible combination of the two attributes). Only a few consumers would want extreme speed at the expense of flexibility or extreme flexibility at very slow speeds. The majority of users would give about equal weight to both attributes, leading to a non-uniform distribution of preferences.

It is likely that positioning strategies that are optimal when consumer preferences are uniformly distributed may not be desirable in markets with non-uniform preferences. Shugan (1987), for example, finds that market share predictions based on the Defender model vary significantly depending on the particular distribution of consumer preference that is assumed. Analysis of positioning strategies of two brands competing in a 
two-dimensional perceptual space leads Carpenter (1989) to conclude that unimodal taste distributions encourage brands to locate at the center of the market when advertising and distribution effects are not prominent. It is important therefore to understand how consumer heterogeneity influences product positioning decisions of firms. Would the strategic impact of price competition continue to dominate even if the market is relatively homogeneous? Would non-uniformity of consumer preferences bestow special advantages to first movers by allowing them to capture majority segments? Would incentives to deter entry vary with different patterns of consumer preference heterogeneity? We seek to answer these questions.

We study the nature of competition among firms by investigating the properties of sub-game perfect Nash equilibria in markets with two, three or four brands and nonuniform consumer preference distributions. Many of the resulting position-price equilibria are different from those obtained for uniform preference distributions. D'Aspermont et al. ( 1979) and Hauser (1988), for example, find that for uniform preference distributions the equilibrium is one of maximal differentiation. With non-uniform preferences, on the other hand, we find that brands are neither clustered nor maximally differentiated. With three brands, for example, we find that the exterior brands do not move away as far as possible from the central brand. They take internal positions, and these positions are related directly to the variance of the distribution of consumer preferences.

We also present results for two and four-firm equilibria. With unimodal symmetric preference distributions there are two equilibria in a duopoly, each a mirror image of the other. When consumers are relatively heterogeneous in their preference for the product attributes, the resulting equilibrium is one of maximal differentiation. However, when consumer preferences are relatively homogeneous, the equilibrium is asymmetric around the modal consumer preference. That is, one brand positions internally while the other chooses a position at the opposite extreme of the product space. Further, the switch from the symmetric to the asymmetric equilibrium happens abruptly as the consumers distribution becomes more concentrated. For four brands, we find equilibria for uniform as well as unimodal distributions. In general, nonuniform distributions lead to results that are markedly different from those obtained for uniform consumer distributions.

The optimal positions of brands depend critically on the total number of brands and the sequence in which they enter the market. To date, most models of competitive brand positioning assume that the number of brands in the market is determined exogenously and that these brands enter (or reposition) simultaneously (Hauser 1988, Neven 1986). In addition to examining simultaneous positioning, we also investigate equilibrium when firms enter sequentially. We assume that early entrants have foresight and are able to predict how later entrants will respond to their positions (Prescott and Visscher 1977). As Lane (1980, 238), argued, sequential entry with foresight is a useful equilibrium concept "because it enables entry to be made endogenous to the model in a meaningful manner." We explore how early entrants can use their positions to deter entry of other brands and how entry deterrence strategies are affected by the distribution of consumer preferences. We find that the equilibrium configuration under sequential entry differs from that under simultaneous positioning.

The rest of the paper is organized as follows: Section 2 defines the main features of our model. Section 2.1 briefly states our assumptions regarding the product space. In $\S 2.2$ we outline our use of the beta distribution to describe the distribution of consumer preferences. Section 2.3 describes the nature of the positioning-price game. Section 3 presents results for the simultaneous entry case. We discuss, in turn, the price-location equilibria for two, three, and four brands. Section 4 looks at positioning strategies when firms enter the market sequentially rather than simultaneously. Section 5 presents some concluding remarks. 


\section{The Model}

\subsection{The Nature of the Product Space}

The first step in positioning a brand is to distinguish the salient qualities or attributes on which brands differ. These attributes comprise the product space in which brands compete. A brand's relative position in this space partially determines its ability to attract customers in the competitive marketplace. We follow Hauser and Shugan's (1983) Defender framework in our assumptions regarding the product space. Each brand in our model is characterized by its position in a two-dimensional space. The particular position a brand occupies in this space is determined by: a) the level of two physical attributes $\left(x_{1}, x_{2}\right)$ possessed by each unit of the brand, and $\left.\mathrm{b}\right)$ the price of the brand. For example, assume that a unit of brand $j$ has $x_{1 j}$ and $x_{2 j}$ units respectively of the two attributes, and its price is $p_{j}$. Brand $j$ 's position in the per dollar product space is then given by the coordinates $\left(x_{1 j} / p_{j}, x_{2 j} / p_{j}\right)$. The utility consumer $i$ receives from this brand is

$$
U_{i}=w_{i 1}\left(x_{1 j} / p_{j}\right)+w_{i 2}\left(x_{2 j} / p_{j}\right)
$$

where $w_{i 1}$ and $w_{i 2}$ are the relative weights the consumer places on attributes 1 and 2 respectively. Let $\gamma_{i}=\arctan \left(w_{i 2} / w_{i 1}\right)$ be the address for consumer $i$. This is the angle that the consumer's indifference curve makes with the vertical axis. This angle represents the consumer's relative preference for the two attributes and varies between 0 and 90 degrees. A consumer who considers the first attribute as much more important than the second has a low $\gamma$ value, while one who places more weight on the second and less weight on the first has a $\gamma$ near 90 degrees. Brands too can be identified by unique addresses. When all brands have the same price, they can each be addressed by $\theta$, the angle made by a ray connecting the brand's coordinate position to the origin.' Assume that consumer tastes are distributed according to a density function $f(\gamma)$, such that

$$
\int_{0}^{90} f(\gamma) d \gamma=1
$$

Then the market share of brand $j, D_{j}$, is given by:

$$
D_{j}=\int_{\gamma_{j h}}^{\gamma_{j k}} f(\gamma) d \gamma
$$

where $\gamma_{j h}$ and $\gamma_{j k}$ are angles made with the vertical axis by the line segments joining the position of brand $j$ with the positions of the lower adjacent $(h)$ and upper adjacent $(k)$ brands. These angles are shown in Figure 1. A consumer with address $\gamma_{j k}$ is indifferent between brand $j$ and brand $k$. Thus, the limits on the integral in Equation (3) represent the boundaries of the firm's market. The location of the boundary depends upon the positions and prices of the brands. The boundary between brands $j$ and $h$, for example, is given by: $\gamma_{j h}=\arctan \left[\left(p_{j} \cos \left(\theta_{h}\right)-p_{h} \cos \left(\theta_{j}\right)\right) /\left(p_{h} \sin \left(\theta_{j}\right)-p_{j} \sin \left(\theta_{h}\right)\right)\right]$. The market for a lower peripheral brand extends from 0 to $\gamma_{j h}$, and that of an upper peripheral brand from $\gamma_{j k}$ to 90 . Clearly, $\gamma_{j h}$ and $\gamma_{j k}$ are continuous functions of $p_{h}, p_{j}$ and $p_{k}$. Most importantly, the demand $D_{j}$ that depends on $\gamma_{j h}$ and $\gamma_{j k}$ is continuous in $p_{j}$, as well as in $p_{h}$ and $p_{k}$. Thus, the "Defender" model avoids the discontinuity problems of the original Hotelling (1929) model.

Given the above characterization of the product space and consumer preferences, we seek the equilibrium positions and prices when brands compete with each other to

\footnotetext{
${ }^{1}$ These types of models-in which consumers and firms or brands can be identified by points in perceptual or geographic space-are often called address models. See Archibald, Eaton and Lipsey (1986) and Lancaster (1990).
} 
$\mathrm{x} 2 / \mathrm{p}$

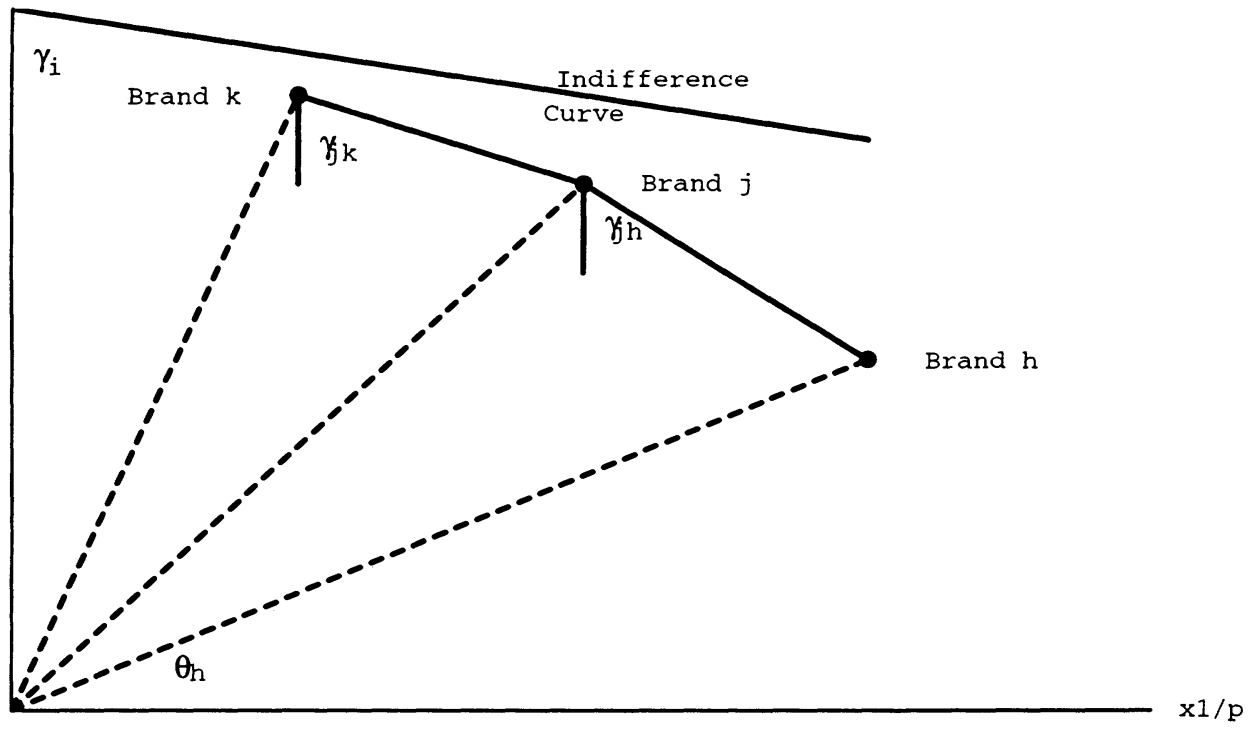

FIGURE 1. The Product Space.

maximize their own profits. Initially we assume that a given number of efficient brands already exist in the market and no entry or exit is allowed. Further, we assume that brands cannot change their rank ordering along the horizontal axis of the product space. This assumption eliminates the possibility of brands changing their positions radically. We also assume that all consumers have a finite and common reservation price for the product category. ${ }^{2}$

Regarding costs, we assume that each brand has the same marginal cost of production, $c$, which is constant and independent of the position for the brand or the level of output. When studying sequential entry situations, we also assume that firms incur a fixed cost $F$ of entering the market. Given this framework, we can write brand $j$ 's profit function as:

$$
\Pi_{j}=\left(p_{j}-c\right) \int_{\gamma_{j h}}^{\gamma_{j k}} f(\gamma) d \gamma-F
$$

Since the demand function is continuous in prices, so is the profit function.

\subsection{Distribution of Consumer Preferences}

So far, our model is similar to many spatial economics models (e.g., D'Aspremont, Gabszewicz and Thisse 1979, Economides 1989, Hotelling 1929, and Hauser 1988). As noted, our main point of departure from these models is the manner in which consumer preferences are distributed. Unlike earlier models, which assume uniform consumer preferences, we allow more general consumer preference distributions. Specifically, we assume that the distribution of consumer preferences, $f(\gamma)$, follows a generalized beta distribution over the spectrum of consumer preferences; that is $[0,90]$ degrees. In other words:

$$
f\left(\gamma ; \alpha_{1}, \alpha_{2}\right)=\frac{\Gamma\left(\alpha_{1}+\alpha_{2}\right)(\gamma)^{\alpha_{1}-1}(90-\gamma)^{\alpha_{2}-1}}{\Gamma\left(\alpha_{1}\right) \Gamma\left(\alpha_{2}\right)(90)^{\alpha_{1}+\alpha_{2}-1}}
$$

where $\Gamma$ is the gamma function and $\alpha_{1}$ and $\alpha_{2}$ are the parameters of the beta distribution.

\footnotetext{
${ }^{2}$ See Hauser ( 1988 ) for further discussion of these assumptions.
} 
The relative values of $\alpha_{1}$ and $\alpha_{2}$ determine the shape of the beta distribution. When they are both equal to $1, f(\gamma)$ is distributed uniformly. The distribution is symmetric when $\alpha_{1}=\alpha_{2}=\alpha$. The variance of the symmetric beta is inversely related to $\alpha$. For $\alpha>1$, the higher the value of $\alpha$, the more peaked and concentrated is the distribution. Conversely, for $\alpha<1$, the lower the value of $\alpha$, the more $\mathrm{U}$-shaped and more polarized is the distribution. ${ }^{3}$

Although other types of nonuniform distributions (e.g., the normal distribution) could be posited, we chose the beta distribution because it is very flexible and can be constrained to the interval $[0,90]$ without need for truncation. Moreover, the beta distribution has been widely used in the marketing literature to characterize consumer heterogeneity. A number of studies have found that the beta and the Dirichlet distributions fit empirical distributions of consumer purchases very well (e.g., Ehrenberg 1959, 1972). In a recent study, Waarts, Carree, and Wierenga (1991) extended Shugan's (1987) procedure for mapping brand positions in a Defender framework from scanner data. In deriving their maps these authors, too, assumed that consumer preferences followed a beta distribution. In addition, as Shugan (1987) notes, the advantage of the beta in this context is that it allows a nested test for the uniform distribution. With the beta distribution one can vary the degree of heterogeneity in consumer preferences while holding constant the number of consumers in the market. This allows us to test the sensitivity of results to the level of heterogeneity in consumer preferences. For symmetric unimodal distributions, the level of heterogeneity in consumer preferences can be measured by the parameter $\alpha$. The higher the value of $\alpha$, the more peaked the distribution and higher the level of homogeneity in preferences.

\subsection{The Nature of the Game}

We assume that firms compete in a game of two stages. In the first stage, firms choose positions, and in the second stage they choose prices. In the second stage, when choosing prices, firms consider the positions of all firms as fixed. This stage is sometimes referred to as the price subgame. In the first stage, when choosing its position, each firm correctly anticipates the effect of its position choice on the equilibrium prices determined in the second stage. This correct anticipation of the influence of position on price is formalized in the subgame perfect equilibrium concept, as seen below.

Before going into the formal definitions, let us note that the intuition behind this twostage structure lies in the fact that prices are more flexible than positions in the short run. Thus, the second stage of the game can be interpreted as the short run where only prices are flexible, while the first stage can be viewed as the long-term when strategic decisions to determine the brand's position in the product space are taken. Once made, a brand's position is assumed to be permanent because of the high cost of repositioning.

Some may argue that while a firm in this model has foresight to anticipate price competition in the positioning stage, it takes the competitors' prices as given when setting its own price. Although this may seem limiting at first glance, we feel that the model is a good representation of the world in which firms adjust and re-adjust their prices in competitive markets until they arrive at an "equilibrium" through a process not unlike that underlying Nash equilibrium.

Formally, the profits of firm $j, j=1, \ldots, n$, depend on the vector of prices charged by all firms, $\vec{p}=\left(p_{1}, p_{2}, \ldots, p_{n}\right)$, and on the vector of their positions, $\vec{\theta}=\left(\theta_{1}, \theta_{2}, \ldots\right.$, $\left.\theta_{n}\right)$,

$$
\Pi_{j}=\Pi_{j}(\vec{p}, \vec{\theta}) \quad j=1, \ldots, n .
$$

\footnotetext{
${ }^{3}$ When $\alpha_{1}>(<) \alpha_{2}, f(y)$ is negatively ( positively) skewed. The mode of the beta distribution is given by $\left[90\left(\alpha_{1}-1\right)\right] /\left(\alpha_{1}+\alpha_{2}-2\right)$. The variance is $\left(90^{2} \alpha_{1} \alpha_{2}\right) /\left[\left(\alpha_{1}+\alpha_{2}+1\right)\left(\alpha_{1}+\alpha_{2}\right)^{2}\right]$.
} 
In the last stage of the game, firms choose prices noncooperatively, considering all positions as fixed. The equilibrium prices $p_{j}^{*}(\vec{\theta}), j=1, \ldots, n$, are the solution to the system of equations,

$$
\partial \Pi_{j}(\vec{p}, \vec{\theta}) / \partial p_{j}=0 \quad j=1, \ldots, n
$$

provided that each profit function $\Pi_{j}$ is quasi-concave (single-peaked) in its own price $p_{j}$, and locally concave in $p_{j}$ in the neighborhood of $p_{j}^{*}$. Let the vector of equilibrium prices be

$$
\vec{p}^{*}(\vec{\theta})=\left(p_{1}^{*}(\vec{\theta}), p_{2}^{*}(\vec{\theta}), \ldots, p_{n}^{*}(\vec{\theta})\right)
$$

In the first stage, firms anticipate the effect of their positions on the equilibrium prices, i.e., the influence of $\vec{\theta}$ on $\vec{p}^{*}$. Thus, the equilibrium profit for the second stage become the first stage objective function for firm $j$. This recursion to the first stage requires that the equilibrium of the price subgame is uniquely defined for each vector of positions $\vec{\theta}$.

$$
\Pi_{j}^{f}(\vec{\theta})=\Pi_{j}\left(\vec{p}^{*}(\vec{\theta}), \vec{\theta}\right)
$$

The first-stage ${ }^{4}$ decisions depend on whether firms choose positions simultaneously or in sequence. Under simultaneous positioning, each firm chooses its position without knowing the positions of its competitors. Thus, there is a strategic symmetry among the competitors. In the first stage, each firm $j$ chooses noncooperatively its position $\theta_{j}$ to maximize $\Pi_{j}^{f}(\vec{\theta})$, i.e., it solves

$$
\partial \Pi_{j}^{f}(\vec{\theta}) / \partial \theta_{j}=\sum_{k=1}^{n}\left(\partial \Pi_{j} / \partial p_{k}\right)\left(d p_{k}^{*} / d \theta_{j}\right)+\partial \Pi_{j} / \partial \theta_{j}=0, \quad j=1, \ldots, n .
$$

The non-cooperative positioning equilibrium ${ }^{5}$ in positions, $\vec{\theta}^{*}=\left(\theta_{1}^{*}, \theta_{2}^{*}, \ldots, \theta_{n}^{*}\right)$, is established as a solution to the above system of equations. ${ }^{6}$ The overall subgameperfect equilibrium, then, is a set of positions $\vec{\theta}^{*}$ and the corresponding vector of equilibrium prices $\vec{p}^{*}\left(\vec{\theta}^{*}\right)$.

\section{Competitive Equilibrium with Simultaneous Entry}

In this section we look at equilibrium positions when the number of brands is fixed exogenously and when firms choose positions simultaneously. We assume, without loss of generality, that the fixed cost $F$ is zero. We first discuss duopoly markets.

\subsection{Equilibrium for Two Brands}

It is now generally accepted that in the "Defender" model when consumers are uniformly distributed and brands compete in position as well as price, the resulting equilibrium configuration is one of maximal differentiation. That is, the brands position themselves as far as possible from each other (Hauser 1988). Our results show that the equilibrium configuration depends on the nature of consumer preference. Maximal differentiation is optimal only when consumer preferences are heterogeneous. For unimodal and sufficiently concentrated distributions of preferences, we find that one of the brands chooses an interior position in equilibrium. In marketing terms, this implies that

\footnotetext{
${ }^{4}$ The superscript " $f$ " in the equations denotes the first stage.

${ }^{5}$ Note that firm $j$ considers the positions of all other firms as fixed, but correctly calculates its influence on profits through the equilibrium prices, $\sum_{k=1}^{n}\left(\partial \Pi_{j} / \partial p_{k}\right)\left(d p_{k}^{*} / d \theta_{j}\right)$.

${ }^{6}$ Firm $j$ considers the effects on profits of changes in its location $\theta_{j}$ only, i.e., $\partial \Pi_{j}^{f}(\theta) / \partial \theta_{j}$, while keeping $\theta_{i}$, fixed, $i \neq j$. Therefore, comparisons of profits where more than one position has been changed (such as across pairs of symmetric positions) are not sufficient to establish a subgame perfect equilibrium.
} 
one brand focuses on the majority segment, while the other follows a niche strategy. We first focus on the price subgame and then discuss the positioning configuration.

3.1.1. Price Competition: Existence and Uniqueness of Equilibrium. In the last stage of the game, firms choose prices. Firm $j$ maximizes $\Pi_{j}(\vec{p}, \vec{\theta})$ with respect to $p_{j}$, keeping all other arguments fixed. Since each profit function is a continuous and bounded function defined on a compact convex set ( subset of $R^{n}$ ), we can utilize the non-cooperative equilibrium existence theorems of Nash (1951) and Debreu (1952). These theorems show that a sufficient condition for the existence of a pure strategy price equilibrium as a solution to the first order conditions ( 7 ) is that each profit function $\Pi_{j}$ is quasi-concave in $p_{j}$ and locally concave in the neighborhood of the equilibrium price. Further, Caplin and Nalebuff $(1991,38)$, show that a sufficient condition for quasi-concavity of $\Pi_{j}$ in $p_{j}$ is that the reciprocal of the demand, $1 / D_{j}\left(p_{j}\right)$ is convex in own price $p_{j}$.

Furthermore, a unique price equilibrium is required for each vector of product positions in order to define a subgame-perfect equilibrium in the overall position-price game. To verify uniqueness, we utilize Rosen's ( 1965) extension of the Gale-Nikaido ( 1965) univalence theorem. This theorem states that, if profit functions fulfill the equilibrium existence requirements stated in the previous paragraph, and further the profit functions have a negative quasi-definite Jacobian in their concave portion, then the price subgame has a unique equilibrium. In our setup, the Jacobian is

$$
J=\left(\begin{array}{cc}
\partial^{2} \Pi_{1} / \partial p_{1}^{2} & \partial^{2} \Pi_{1} / \partial p_{1} \partial p_{2} \\
\partial^{2} \Pi_{2} / \partial p_{2} \partial p_{1} & \partial^{2} \Pi_{2} / \partial p_{2}^{2}
\end{array}\right) .
$$

Matrix $J$ is negative quasi-definite if $J^{*} \equiv J+J^{T}$ is negative definite, ${ }^{7}$ where the superscript $T$ denotes a transposed matrix. ${ }^{8}$

In our model, for unimodal beta densities, the profit function of each firm is quasiconcave in its own price as pictured in Figure 2. We establish the quasi-concavity of $\Pi_{j}$ in $p_{j}$ by verifying the convexity of $1 / D_{j}$ in $p_{j}$ on a dense grid of $p_{i}$ and $p_{j}$ for given positions of $\theta_{i}$ and $\theta_{j}$ also on a dense grid. Given the continuity and smoothness of the second derivatives of the demand function, the convexity of $1 / D_{j}$ on a dense grid is sufficient to establish the convexity of $1 / D_{j}$ for all $p_{i}$ and $p_{j}$ in the compact domain. The exact form of the demand functions and the algorithm used are described in the Appendix. ${ }^{9}$

After determining existence of price equilibrium, we also determine that this equilibrium is unique. We establish uniqueness by verifying the negative quasi-definiteness of the Jacobian on a dense grid of $p_{i}$ and $p_{j}$ for given positions for $\theta_{i}$ and $\theta_{j}$ on a dense grid. Given the continuity and smoothness of the second derivatives of the demand function, the negative quasi-definiteness of the Jacobian on the dense grid is sufficient to establish

\footnotetext{
${ }^{7} \mathrm{~A}$ matrix is negative definite if the determinants of its principal minors are alternating in sign, starting with a negative sign for the first principal minor.

${ }^{8}$ For symmetric games, i.e., if $\partial^{2} \Pi_{1} / \partial p_{1}^{2}=\partial^{2} \Pi_{2} / \partial p_{2}^{2}$ and $\partial^{2} \Pi_{1} / \partial p_{1} \partial p_{2}=\partial^{2} \Pi_{2} / \partial p_{1} \partial p_{2}, J$ negative quasidefinite is equivalent to $J$ negative definite, as simple calculation shows. However, for asymmetric games, such as ours, for general positions, negative quasi-definiteness is less restrictive than negative definiteness. For details see Friedman (1986).

${ }^{9}$ Unfortunately, we cannot directly apply the theorems in Caplin and Nalebuff (1991) which depend upon the Prekopa-Borell theorem on $\rho$-concavity of aggregate demand functions. There is no general theorem on $\rho$ concavity of our demand function given the per dollar utility function and the beta distribution on the arctangent of consumer weights we employ. In fact, using the Caplin-Nalebuff approach we can prove analytically that $1 /$ $D_{j}$ is convex for a beta distribution of the consumer's ratio of weights. But the tangent transformation, which is essential for the Defender model, does not preserve or enhance concavity; thus, it does not allow a straightforward extension of this result. Nevertheless, the success of our algorithm provides very strong evidence that an analytical proof can be written for the proposition that the beta distribution on the consumer's angle results in $1 / D_{j}$ convex.
} 


\section{profit 1}

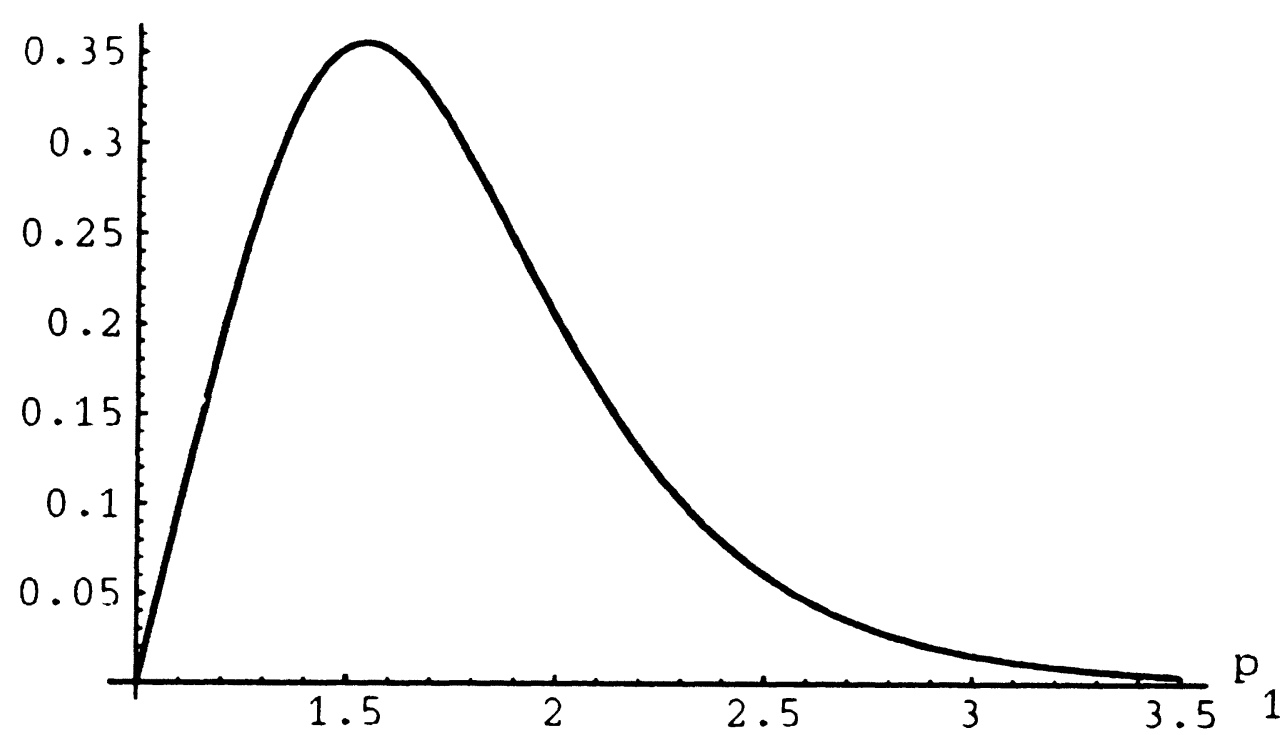

Figure 2. Profits for Firm 1, for $\alpha=12, \theta_{1}=30, \theta_{2}=90$ and $p_{2}=p_{2}^{*}$.

negative quasi-definiteness for all prices. We check for existence and uniqueness for $\alpha$ $=3,5,7,9,12$. Hauser and Wernerfelt (1988) had established existence and uniqueness for $\alpha=1$.

3.1.2. Competition in Positions. In the first stage of the game, firms choose positions, anticipating the equilibrium prices in the second stage price subgame. In particular, each firm anticipates the influence of a change in its position on the prices of all firms. The profit function of firm 1 , in the positioning stage is

$$
\Pi_{1}^{f}(\vec{\theta})=\Pi_{1}\left(\vec{p}^{*}(\vec{\theta}), \vec{\theta}\right) .
$$

As firm 1 changes its position, profits change according to

$$
\frac{d \Pi_{1}^{f}(\vec{\theta})}{d \theta_{1}}=\frac{\partial \Pi_{1}}{\partial \theta_{1}}+\frac{\partial \Pi_{1}}{\partial p_{1}} \frac{d p_{1}^{*}}{d \theta_{1}}+\frac{\partial \Pi_{1}}{\partial p_{2}} \frac{d p_{2}^{*}}{d \theta_{1}}=\frac{\partial \Pi_{1}}{\partial \theta_{1}}+\frac{\partial \Pi_{1}}{\partial p_{2}} \frac{d p_{2}^{*}}{d \theta_{1}}
$$

because $\partial \Pi_{1} / \partial p_{1}=0$ from profit maximization of firm 1 in the last stage. At constant prices, as firm 1 positions itself further inwards and closer to its opponent, its demand increases, and so does its profit; therefore, $\partial \Pi_{1} / \partial \theta_{1}>0$. Now, because the products are substitutes, $\partial \Pi_{1} / \partial p_{2}>0$. When the products become closer substitutes (as $\theta_{1}$ increases) the subgame equilibrium prices decrease and $d p_{2}^{*} / d \theta_{1}<0$. Therefore, the second term in the RHS of (13) is negative, and a priori the sign of $d \Pi_{1}^{f}(\vec{\theta}) / d \theta_{1}$ is indeterminate since it is the sum of two terms of opposite signs.

Figure 3 depicts the profits of Firm 1 in the first stage as a function of its position, when the position of the second firm is fixed $\left(\theta_{2}=90\right)$ and for different $\alpha$ parameters of the beta distribution. Notice that the relationship between Firm l's profit and its position depends on the level of heterogeneity in the market (as measured by $\alpha$ ). As the firm moves to the right, away from $\theta_{1}=0$, the function $\Pi_{1}\left(\theta_{1}\right)$ decreases for all $\theta_{1}$ when preferences are heterogeneous ( $\alpha$ is low); decreases and then increases for moderate homogeneity; and increases when preferences are highly homogeneous. This behavior is the result of the interplay between the market share gained from moving inside and the 
$\alpha=3$

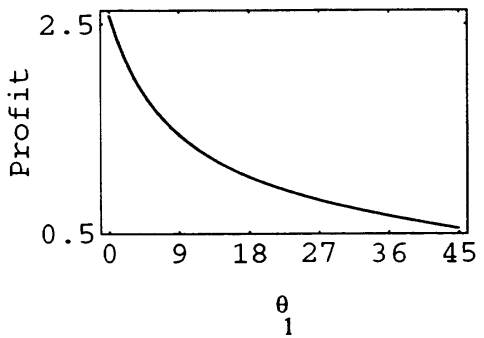

$\alpha=11.2$

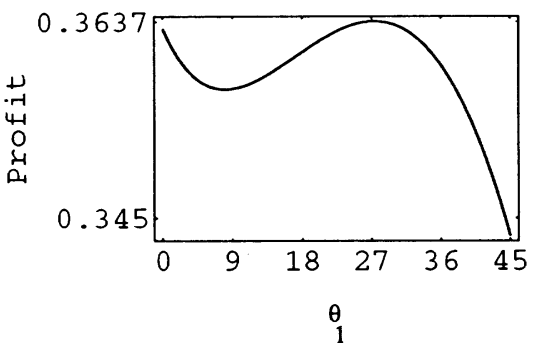

$\alpha=11$

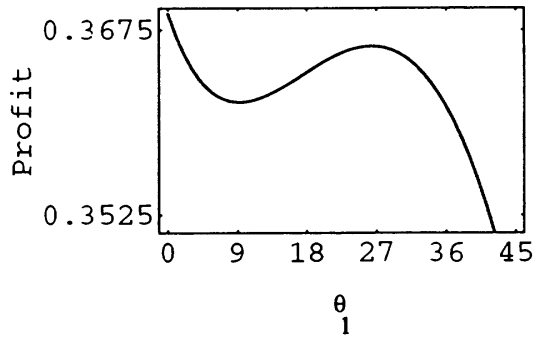

$\alpha=13$

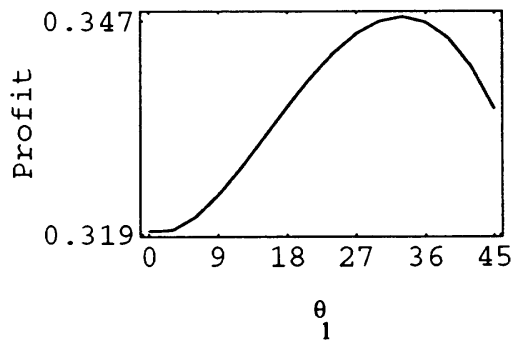

Figure 3. Profits of Brand $I$ as a Function of Its Position for Selected Values of $\alpha$.

price competition that results from such moves. When $\alpha$ is high, as $\theta_{1}$ comes further inside, the increase in demand overshadows the decrease in price, and profits start increasing in $\theta_{1}$, eventually reaching a peak. As $\alpha$ increases, the game becomes more competitive, but prices decrease only slightly for all $\theta_{1}$. Thus the shape of the profit function is driven more by changes in market share rather than changes in the equilibrium price.

Consider, for example, the case when $\alpha=11.2 . \Pi_{1}^{f}\left(\theta_{1} ; 90\right)$ initially falls as the brand moves its position inward from zero (see Figure $3 \mathrm{c}$ ). Profits reach a minimum at $\theta_{1}$ $=8$, and then increase, reaching a maximum at $\theta_{1}=27$. To understand the factors that shape the profit function, consider the situation when $\theta_{1}=8, \theta_{2}=90$. The lower brand's market share in this situation is 0.539523 and its equilibrium price is 1.66207 . Its profit, therefore, is 0.357202 . Now let brand 1's position change from 8 degrees to 9 degrees. The move toward the other brand intensifies price competition and reduces the equilibrium price to 1.6559 . But, brand 1's market share increases to 0.544678 . Thus, profit, at this new position, is 0.357254 , which is higher than before. Within the interval ( $8<\theta_{1}$ $<27$ ) the lower brand has an incentive to move inward since the gain in market share compensates for the reduction in margin. For $0<\theta_{1}<8$ and $\theta_{1}>27$, on the other hand, the gain in market share is not enough to compensate for the lower margin resulting from reduced prices.

In Figure 3 as consumer preferences become less heterogeneous (as $\alpha$ increases) the right peak of the profit function rises while the left peak falls. This is because, as $\alpha$ increases, there is a bigger demand reward for firm 1 when it is near the peak of the density function. Eventually, for $\alpha>11.1$, the right peak of the profit function is higher, precipitating the choice of an interior position of firm 1.

Figure 4 shows the best reply functions in positions at the first stage of the game; that is, $\theta_{1}^{+}\left(\theta_{2}\right)$ and $\theta_{2}^{+}\left(\theta_{1}\right)$ for $\alpha=13$. Recall that in this case one firm prefers an interior 


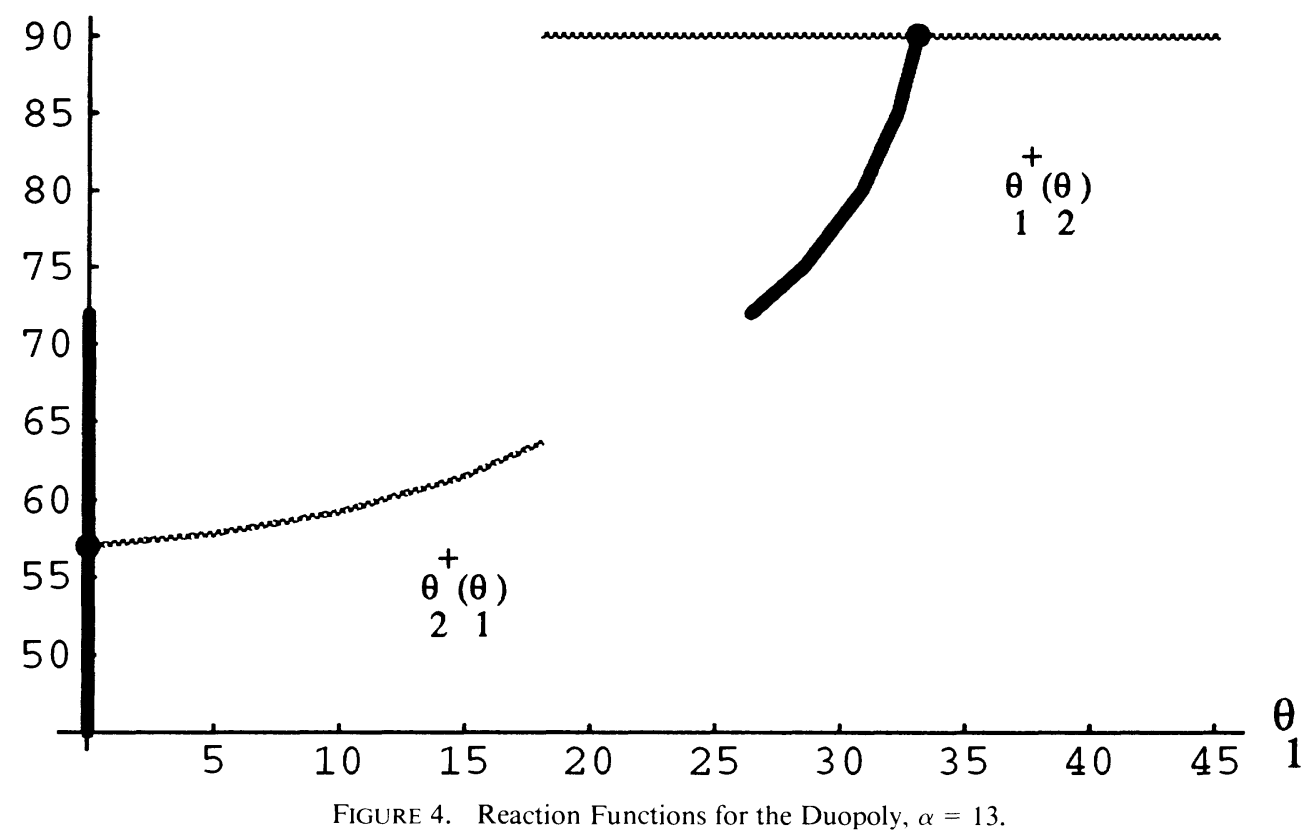

position. The points of intersection (indicated by bullets in the diagram) of the two reaction functions give the two equilibrium configurations. In the first equilibrium, $\theta_{1}$ is positioned at 0 degrees and $\theta_{2}$ at 57.5 degrees. The second equilibrium is the mirror image of the first and has $\theta_{1}$ at 32.5 degrees and $\theta_{2}$ at 90 degrees. Notice that, despite the discontinuities of the best reply functions (precipitated by the lack of quasi-concavity of profits with respect to the position), for some $\theta$ s equilibrium exists. This is indeed a case where the typical sufficient condition for existence (quasi-concavity) fails but an equilibrium still exists. ${ }^{10}$

Figure 5 shows the subgame-perfect equilibrium positions for two brands for markets with symmetric and unimodal consumer preferences. For markets that have a low degree of homogeneity ( characterized by beta distributions with $1<\alpha<11.1$ ) the equilibrium positions are at $\theta_{1}^{*}=0, \theta_{2}^{*}=90$. Since the preference distribution is relatively heterogeneous there are no positions that give preferential access to large groups of consumers and there is little incentive for brands to cluster. Firms, therefore, move as far away as possible to reduce the impact of price competition.

For markets with symmetric and unimodal consumer preferences that have a high degree of homogeneity (beta distributions with $\alpha \geq 11.1$ ), there are two equilibria. As is clear from the previous discussion pertaining to best response functions, these equilibrium configurations yield asymmetric product positions and each configuration is a mirror image of the other. In each configuration, one brand positions internally while the other chooses a position at the opposite extreme of the product space. That is, in the first equilibrium the lower brand is positioned at $\theta_{1}^{*}=0$, and the upper brand is positioned

\footnotetext{
${ }^{10}$ A similar example of existence of equilibrium despite the lack of quasi-concavity can be found in Economides (1986a: b), although this happens in the price subgame. unlike the present situation.
} 


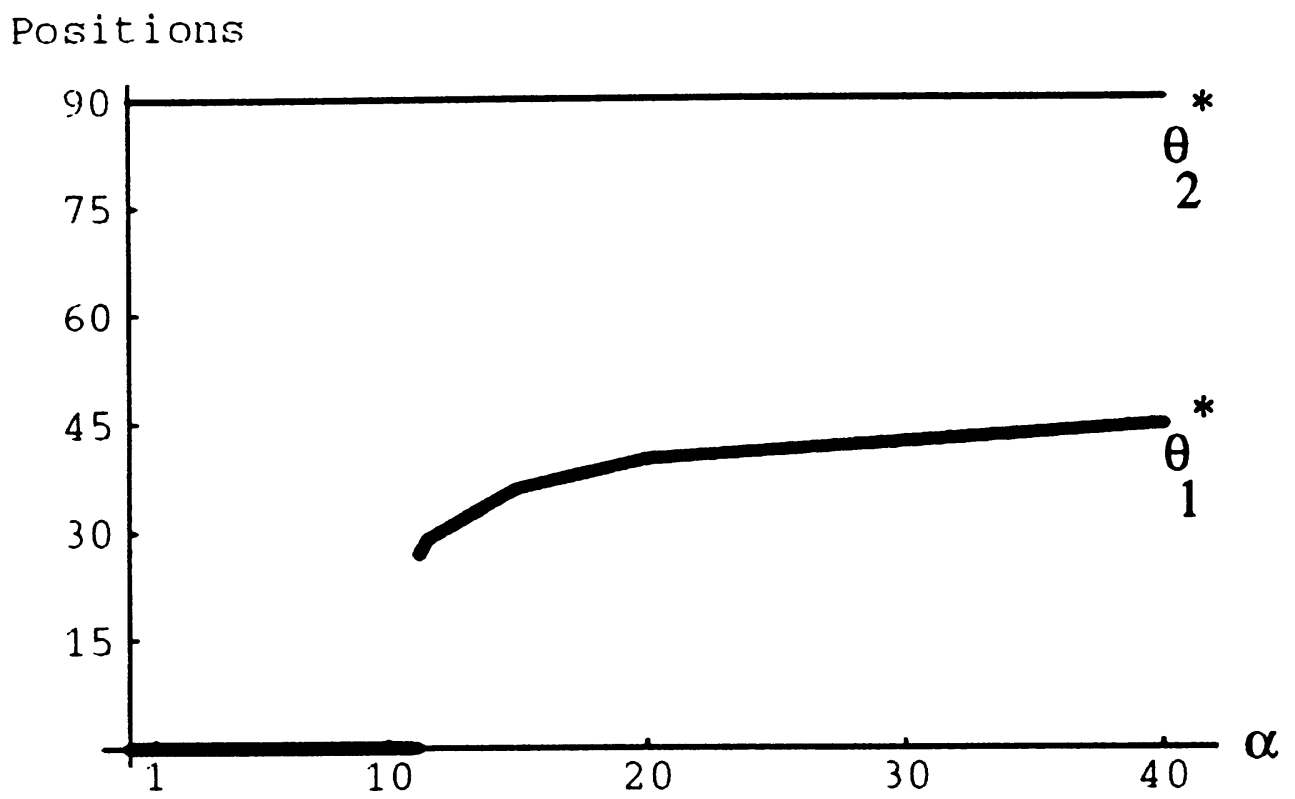

FIgURE 5. Position Equilibria for Two Brands.

internally $\left(45<\theta_{2}^{*}<90\right)$. In the second (mirror image) equilibrium, firm 1 locates at $\theta_{1}^{* *} \in(0,45)$, and firm 2 locates at $\theta_{2}^{* *}=90$. The position of the internal brand depends on the degree of homogeneity in consumer preferences. Note, in Figure 5, the abrupt change in $\theta_{1}^{*}$ at $\alpha=11.1$.

Table 1 presents information on the equilibrium positions, profits, prices and market shares for selected values of $\alpha$. For all preference distributions with $\alpha<11.1$, the equilibrium pattern is one of maximal differentiation and the two brands have the same price, equal market shares, and equal profits. Although the equilibrium locations remain the same, equilibrium price and profits increase with higher levels of heterogeneity in consumer preferences (lower values of $\alpha$ ). Heterogeneity reduces the level of price rivalry and give firms greater freedom to raise prices. When consumer preferences are uniform (extreme heterogeneity), price rivalry is less intense and the assumption of finite consumer

TABLE 1

Equilibrium Configurations for Two Brands (For Selected Values of $\alpha$ )

\begin{tabular}{lccccccc}
\hline$\alpha$ & $\theta_{1}^{*}$ & $\theta_{2}^{*}$ & $p_{1}^{*}$ & $p_{2}^{*}$ & $\pi_{1}^{*}$ & $\pi_{2}^{*}$ & $m_{1}^{*}$ \\
\hline 1 & 0 & 90 & $r$ & $r$ & $.5(r-c)$ & $.5(r-c)$ & 0.50 \\
3 & 0 & 90 & 6.163 & 6.163 & 2.582 & 2.582 & 0.50 \\
6 & 0 & 90 & 2.382 & 2.382 & 0.691 & 0.691 & 0.50 \\
10 & 0 & 90 & 1.804 & 1.804 & 0.402 & 0.402 & 0.50 \\
11.1 & 0 & 90 & 1.732 & 1.732 & 0.366 & 0.366 & 0.50 \\
11.2 & 27 & 90 & 1.571 & 1.261 & 0.364 & 0.095 & 0.63 \\
12 & 30 & 90 & 1.540 & 1.223 & 0.355 & 0.076 & 0.66 \\
16 & 37 & 90 & 1.464 & 1.142 & 0.333 & 0.040 & 0.70 \\
20 & 40 & 90 & 1.429 & 1.109 & 0.323 & 0.027 & 0.75 \\
40 & 44.8 & 90 & 1.376 & 1.057 & 0.314 & 0.009 & 0.84 \\
\hline
\end{tabular}

For each $\alpha>11.1$ there is an alternate equilibrium that is a mirror image of the one shown here. $r$ is the reservation price and $c$ the marginal cost. 
reservation price is required for the equilibrium to exist. As heterogeneity decreases, the price competition intensifies and firms therefore lower prices in order to maintain their market shares.

The pattern of market shares, profits, and prices become markedly different when $\alpha$ exceeds 11.1. As noted, the equilibrium positions are no longer maximally differentiated, and there are two (rather than one) equilibrium patterns. As shown in Table 1, the internal brand in the asymmetric equilibria garners a significantly higher market share and earns a higher profit than the exterior brand. Because of its proximity to the modal consumer preference, the internal brand charges a higher price than the exterior brand. But, since the two equilibrium patterns are mirror images of each other, the final equilibrium cannot be predicted a priori.

It is evident from Table 1 that the position of the interior brand is a function of the level of heterogeneity in consumer preferences. As the preference distribution becomes more peaked ( $\alpha$ increases), the brand's equilibrium position moves toward the center of the market, $\alpha_{1}=45$. Thus, the more homogeneous consumer preferences are, the greater the incentive for the firm to position the brand close to the mode of the preference distribution. The move toward the center of the positioning spectrum by one brand, however, does not draw the second brand inward despite the lower market share. While the second brand can increase market share by moving toward the center of the market, such a move would induce greater price competition and reduce profits because of lower margins. Thus, while one brand positions itself to appeal to the majority of the market that prefers both attributes equally, the other brand positions itself to serve the niche that has a strong preference for one attribute over the other. The niche strategy is more profitable than a "me-too" strategy even though this results in a lower market share.

\subsection{Equilibrium in Three-brand Markets}

3.2.1. Unimodal Distributions. Table 2 shows the equilibrium patterns for the threebrand case for selected values of $\alpha$. For all symmetric and unimodal consumer preference distributions, the equilibrium position of the central brand is at 45 degrees, the mode of the preference distribution. The exterior brands have positions symmetric relative to that

TABLE 2

Equilibrium Configurations for Unimodal Distributions (Three Brands Case)

\begin{tabular}{rrrccc}
\hline$\alpha$ & $\theta_{1}^{*}$ & $p_{1}^{*}$ & $p_{2}^{*}$ & $\pi_{1}^{*}$ & $\pi_{2}^{*}$ \\
\hline 1.0 & 0.0 & 1.4822 & 1.4822 & 0.12055 & 0.24109 \\
1.3 & 7.6 & 1.3234 & 1.3132 & 0.08182 & 0.15469 \\
2.0 & 16.4 & 1.1824 & 1.1727 & 0.04668 & 0.08433 \\
3.0 & 22.4 & 1.1118 & 1.1046 & 0.02878 & 0.05073 \\
4.0 & 25.8 & 1.0802 & 1.0746 & 0.02073 & 0.03602 \\
5.0 & 28.0 & 1.0626 & 1.0580 & 0.01621 & 0.02797 \\
6.0 & 29.4 & 1.0519 & 1.0483 & 0.01341 & 0.02332 \\
7.0 & 30.7 & 1.0437 & 1.0406 & 0.01133 & 0.01955 \\
8.0 & 31.6 & 1.0381 & 1.0354 & 0.00987 & 0.01707 \\
16.0 & 35.0 & 1.0196 & 1.0188 & 0.00501 & 0.00921 \\
20.0 & 36.0 & 1.0157 & 1.0151 & 0.00400 & 0.00743 \\
40.0 & 39.0 & 1.0074 & 1.0069 & 0.00191 & 0.00334 \\
200.0 & 42.0 & 1.0016 & 1.0016 & 0.00041 & 0.00080 \\
400.0 & 43.0 & 1.0008 & 1.0007 & 0.00020 & 0.00036 \\
\hline
\end{tabular}

The position, price and profit for the third brand are always symmetric to those for brand 1 . The position of brand 2, $\theta_{2}=45$, for all cases. 
of the central brand. Consider, for example, the case $\alpha=2$. The equilibrium in this case has the central brand positioned at 45 degrees, the lower peripheral brand is positioned at 16.4 degrees, and the upper peripheral brand is positioned at 73.6 degrees $(=90$ - 16.4). Because of their symmetric positions, the two exterior brands have the same market share, charge the same price and, therefore, earn the same profit. The central brand gets a market share of nearly $49 \%$, charges a price just lower than that of the exterior brands, and earns nearly double the profit. Inspection of the equilibrium solutions for different symmetric unimodal distributions reveals that the features discussed above are common to all. The central brand is always located at the mode of the distribution, and the position of the two exterior brands are symmetric to the mode. The central brand always charges slightly less than the exterior brands and earns substantially more profit than the others.

Figure 6 shows the subgame-perfect equilibrium positions of the three brands as a function of $\alpha$. Note the inward movement of the exterior brands' equilibrium positions as the distribution becomes more peaked and concentrated. When consumer preferences are distributed uniformly, the brand positions are maximally differentiated at equilibrium. The external brands are positioned at 0 and 90 degrees with the central brand at 45 degrees-the same as the pattern found by Hauser (1988). But maximal differentiation is no longer the equilibrium solution when we depart from the uniform distribution assumption. As consumer preferences get more homogeneous, the location of more consumers near the middle of the attribute space draws the exterior brands toward the central brand. This occurs despite the fact that reduced differentiation from the central brand leads to more intense price competition. As the exterior firms move inward, they are forced to reduce their prices. The central brand then reduces its price in response. As a consequence, equilibrium profits for all three brands fall as the consumer distribution gets more peaked. This is seen clearly in Table 2 .

The inward move by the exterior brands as consumer preferences become more homogeneous poses severe penalties for them. As seen in Table 2, profits decline as product

Positions

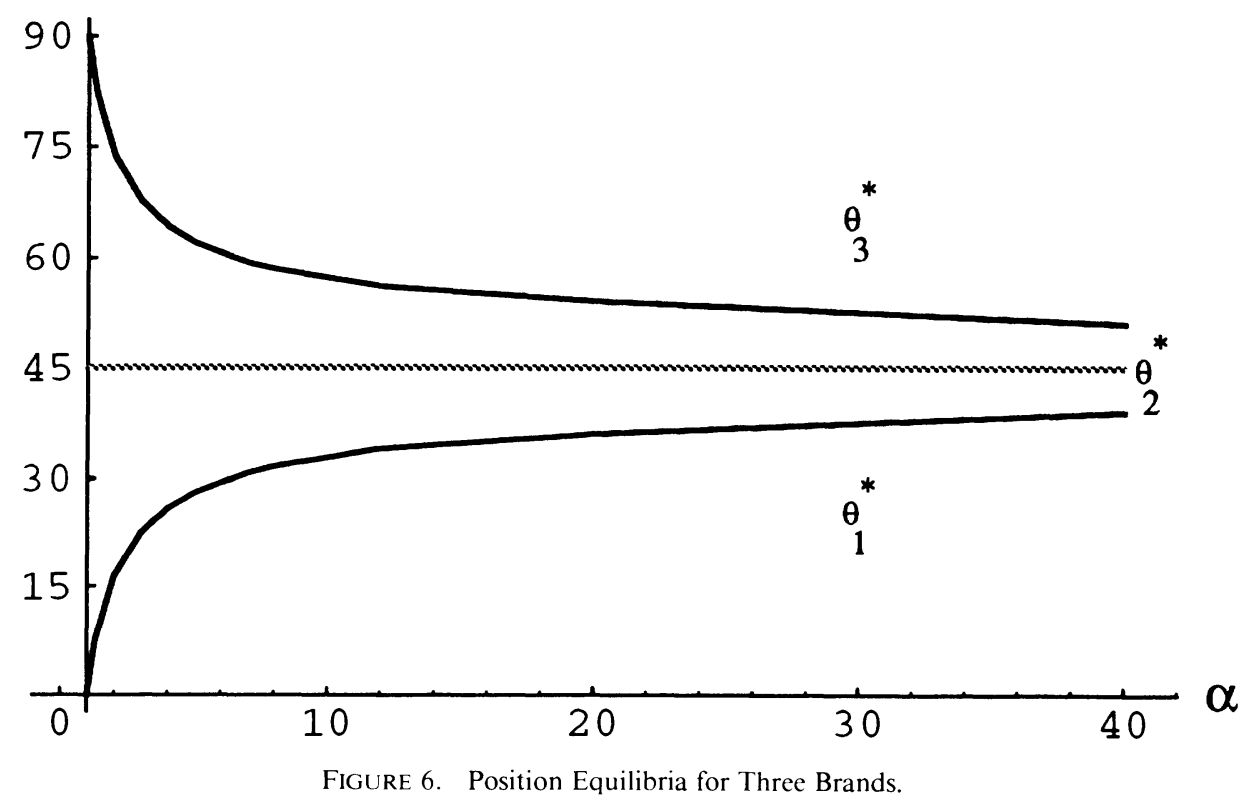


differentiation decreases. The two exterior brands can earn higher profits by forsaking their internal equilibrium positions and moving to $\theta_{1}=0$ and $\theta_{3}=90$, respectively. The maximal differentiation configuration is more profitable for all three brands compared to the subgame-perfect equilibrium. However, maximal differentiation is not an equilibrium, since the two exterior brands have incentives to deviate unilaterally from this configuration. These two brands are caught in a classical prisoner's dilemma. They can both earn more if they differentiate, but it is not profitable for either brand to differentiate unless it is guaranteed that the other will, too. If one brand moves to the edge of the product spectrum unilaterally, the other will remain near the center. The maximal differentiation pattern thus is not self-enforcing.

3.2.2. Bi-Modal Consumer Preferences. Thus far, our focus has been on markets where consumer preferences are distributed in a unimodal fashion, with modal consumers giving equal weights to both product attributes. In this section we examine competitive equilibria when preference distributions are bimodal: One group of consumers prefers the first attribute much more than the second, while the other group prefers the second attribute. Only a few customers prefer products that combine equal levels of both attributes. Such U-shaped preference distributions can be represented by a beta with $\alpha<1.0$. With bimodal consumer preferences and three brands, a subgame perfect equilibrium exists only for moderately polarized preference distributions (beta distributions with .69 $\leq \alpha<1.0$ ). There is no stable equilibrium when the level of polarization is high (beta distributions with $\alpha<0.69$ ).

When consumer preferences are moderately bipolar (distributed beta with $0.69 \leq \alpha$ $<1.0$ ) the equilibrium location pattern is one of maximal differentiation with the three brands positioned at $\theta_{1}=0, \theta_{2}=45, \theta_{3}=90$ respectively. The exterior brands focus on the two modal consumer groups with extreme preferences, while the central brand focuses on consumers who prefer products that combine both attributes. Note from Table 3, however, that despite the exterior brands' focus on modal consumer groups, the central brand still gets a much greater market share because, as a whole, it is preferred by more

TABLE 3

Equilibrium Profits and Prices for U-Shaped Distributions (Three Brand Case)

\begin{tabular}{ccccc}
\hline$\alpha$ & $\pi_{1}^{*}$ & $\pi_{2}^{*}$ & $p_{1}^{*}$ & $p_{2}^{*}$ \\
\hline 0.70 & 0.15891 & 0.25361 & 1.6090 & 1.5306 \\
0.72 & 0.15569 & 0.25281 & 1.5984 & 1.5270 \\
0.74 & 0.15256 & 0.25196 & 1.5882 & 1.5235 \\
0.76 & 0.14953 & 0.25109 & 1.5783 & 1.5200 \\
0.78 & 0.14662 & 0.25022 & 1.5687 & 1.5165 \\
0.80 & 0.14381 & 0.24934 & 1.5595 & 1.5131 \\
0.82 & 0.14110 & 0.24847 & 1.5506 & 1.5098 \\
0.84 & 0.13849 & 0.24760 & 1.5419 & 1.5064 \\
0.86 & 0.13597 & 0.24674 & 1.5336 & 1.5032 \\
0.88 & 0.13353 & 0.24589 & 1.5255 & 1.5000 \\
0.90 & 0.13118 & 0.24505 & 1.5177 & 1.4969 \\
0.92 & 0.12891 & 0.24423 & 1.5101 & 1.4938 \\
0.94 & 0.12671 & 0.24342 & 1.5028 & 1.4908 \\
0.96 & 0.12459 & 0.24263 & 1.4957 & 1.4879 \\
0.98 & 0.12253 & 0.24185 & 1.4888 & 1.4850 \\
1.00 & 0.12055 & 0.24109 & 1.4822 & 1.4822 \\
\hline
\end{tabular}

$$
\pi_{3}^{*}=\pi_{1}^{*} \text { and } p_{3}^{*}=p_{1}^{*} .
$$


Share

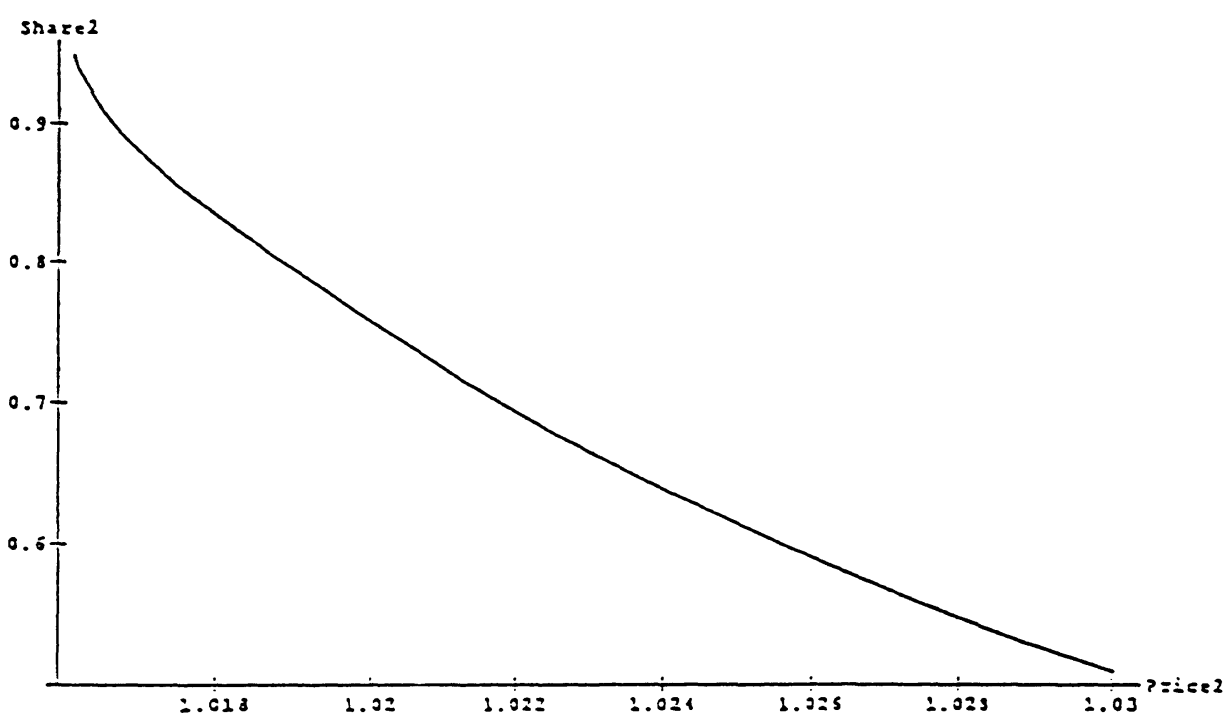

Profit

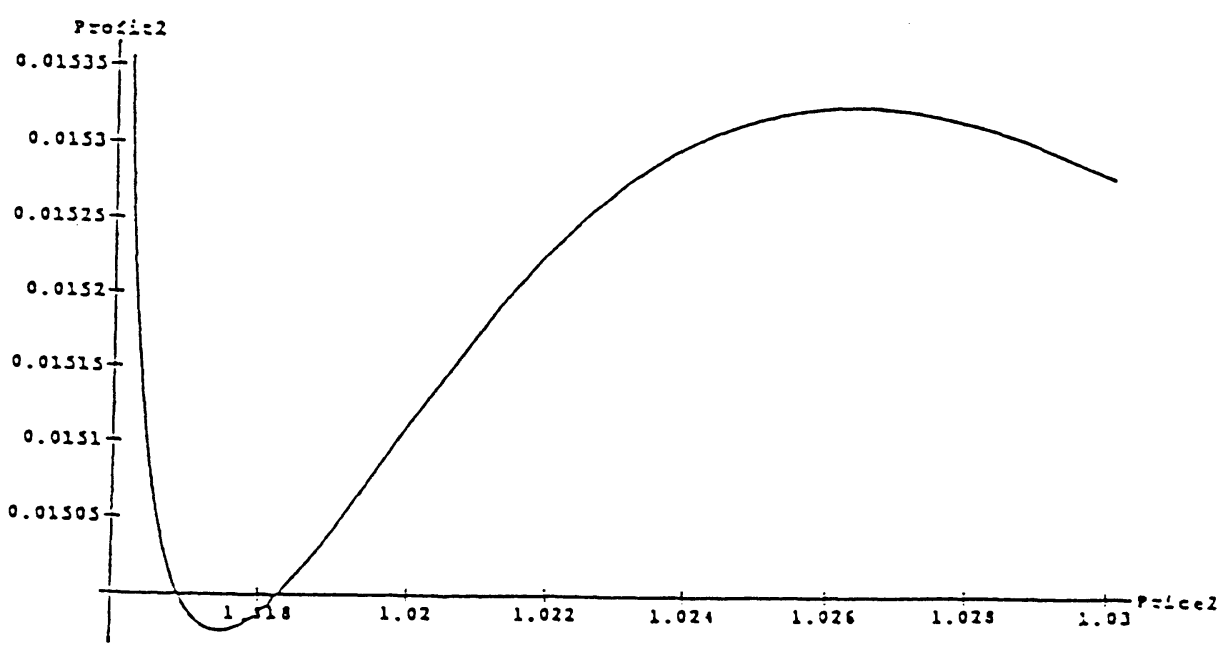

FIGURE 7. Price Undercutting for Bimodal Preferences.

consumers. As one would expect, the market share of the central brand decreases and the shares of the exterior brands increase as the preference distribution departs from uniformity and becomes more U-shaped. The exterior brands gain share and profits as consumer preferences become polarized. For example, the profit of each exterior brand increases from 0.1205 to 0.1589 , an increase of over $28 \%$ as $\alpha$ goes from 1.0 to 0.7 . Interestingly, the profit for the central brand, too, increases, albeit at a slower rate, as the preference distribution becomes more polarized. For example, when $\alpha=0.7$, the profit 
for the central brand is 0.2536 compared to 0.2411 when the distribution is uniform. As consumer preferences become more bipolar, the exterior brands tend to increase price to take advantage of their proximity to consumer preferences. As the prices of the exterior brands increase, the central brand is also able to increase its price and consequently earn higher profit. Thus, one effect of increased polarization of consumer preferences is reduced price rivalry and greater profits for all firms in the industry.

When the preference distribution becomes highly polarized, the market share of the central brand decreases substantially, and its competitive position weakens. This creates an incentive for the second brand to undercut one of the exterior brands in price in order to gain market share. In three-brand markets with consumer preferences distributed beta with $\alpha \leq 0.69$, there is some position $\theta_{2} \in(0,90)$ at which the profit maximizing price for the central brand leads to a configuration in which the central brand dominates at least one of the two brands and garners a very high share of the market. Consider, for example, a beta distribution with $\alpha=0.68$. The best strategy for the second brand in this case is to position at $\theta_{2}=1$ and charge a price $p_{2}=1.016$, which undercuts the price of brand 1 and dominates it.

The undercutting phenomenon can be clearly seen from Figures $7 \mathrm{a}$ and $7 \mathrm{~b}$. Figure $7 \mathrm{a}$ plots $m_{2}\left(p_{2}\left(p_{1}^{*}, p_{3}^{*}\right) \mid \theta_{1}=0, \theta_{2}=1, \theta_{3}=90\right)$ as a function of $p_{2}$, where $m_{2}(\cdot)$ is the market share of the second brand. Figure $7 \mathrm{~b}$ shows the corresponding level of profit for brand 2. As one would expect, brand 2's market share increases as its price falls. When $p_{2}$ falls to 1.016 the second brand dominates brand 1 and garners a market share of approximately $95 \%$. Although brand 3 is not dominated, its market share is only 0.05 (brand 1 has no sales since it is dominated). Undercutting is a viable strategy for brand 2 since the undercutting price exceeds the marginal cost. Recall that all brands have a marginal cost of one. Moreover, as shown in Figure $7 \mathrm{~b}$, the profit from undercutting exceeds profit at any other price. For all cases with $\alpha<0.69$ that we have analyzed, there is a position $\theta_{2}$, at which the central brand can profitably undercut the market. This leads us to believe that in three brand markets equilibrium is unlikely when consumer preferences are highly polarized.

\subsection{Equilibrium in Four-brand Markets}

In addition to the two and three-brand scenarios, we also investigated the four-brand case. We were able to obtain four brand equilibrium for the uniform and symmetric unimodal preference distributions. For uniform preferences, Hauser (1988) had noted that maximal differentiation (i.e., $\theta_{1}=0, \theta_{2}=30, \theta_{3}=60$, and $\theta_{4}=90$ ) is not an equilibrium configuration in the four-brand case. Maximal differentiation does maximize product class profits, and all brands are profitable. But each brand also has a unilateral incentive to move toward the center. Thus, maximal differentiation does not result in a stable configuration. Despite extensive search, Hauser was unable to obtain an equilibrium for four brands. He concluded that a subgame perfect equilibrium in a noncooperative game is unlikely to exist with four brands. He argued that implicit cooperation through repeated playing of the game may lead firms to move and stay at the maximum differentiation positions.

In his search for equilibrium positions, Hauser had speculated that the final configuration would either by symmetrical $\{\theta, 45-\theta, 45+\theta, 90-\theta\}$ or brands would be paired as in Eaton and Lipsey (1975). To seek the equilibrium configuration he systematically changed $\theta$ and evaluated equilibrium prices and profits. A maximum was obtained at $\theta=7.5$ degrees, but each brand had a unilateral incentive to reposition. A change in $\theta$ in his procedure, therefore, changes the position of all four brands. Note from Equation (9) that, in determining subgame perfect positions, brand $j$ considers the effects on profits of changes in its location $\theta_{j}$ only, i.e., while keeping $\theta_{i}(i \neq j)$ fixed. In our procedure, 
we allowed brands to take any feasible position $\left\{\theta_{1}<\theta_{2}<\theta_{3}<\theta_{4}\right\}$. Then a systematic search for equilibrium pattern was conducted by changing the location of each brand in turn while keeping the others fixed.

For the uniform case, we establish the subgame-perfect equilibrium, $\theta_{1}=10, \theta_{2}$ $=35.5, \theta_{3}=54.5, \theta_{4}=80$. The four firms are not maximally differentiated in equilibrium. The brand positions are drawn closer to the center of the product space. The equilibrium configuration exhibits symmetry but its form is much weaker than that imposed by Hauser (1988). In equilibrium, the two exterior brands and the two interior brands form symmetric pairs. The two interior brands are equidistant from the market center, one on each side, and the two exterior brands are equidistant from their respective ends of the market.

This form of symmetry holds even for non-uniform distributions. For $\alpha=1.2$, for example, the equilibrium positions are $\left(\theta_{1}=12, \theta_{2}=36, \theta_{3}=54, \theta_{4}=78\right)$. As consumer preferences become more homogeneous and the distribution peaks at the center of the product space, all brands move toward the center. The general pattern can be represented as $\left\{\delta_{1}, 45-\delta_{2}, 45+\delta_{2}, 90-\delta_{1}\right\}$. In equilibrium, the two exterior brands charge the same price, have the same market share, and the earn the same profit. Similarly, the two interior brands have equal prices, market shares, and profits. The profits of the two interior brands are always higher than that of the exterior ones.

\section{Competitive Equilibrium with Sequential Entry}

The results presented in Section 3 are based on the assumption that all brands enter the market (or reposition) at the same time, and there is no temporal sequence in the positioning decisions of firms. How would the nature of the equilibrium change if firms entered the market sequentially rather than simultaneously? If firms enter in a pre-determined sequence, one would generally expect early entrants to garner higher market shares and earn higher profits because they can capture prime positions. This is especially true when consumer preferences are nonuniform since firms have a strong incentive to position close to the modal consumer preference.

Here we consider that firms choose product positions sequentially in a predetermined sequence. In such a situation there exists a strategic asymmetry in that the later entrant can observe the positions of earlier entrants while incumbent firms must anticipate how their positions will affect the decisions of those entering after them. An incumbent firm has to put itself in the shoes of the later entrant and asks how it would behave in the same circumstance. Based on its expectations regarding competition, the $i$ th firm enters the market with a single brand if its anticipated profit is greater than the fixed cost of entry. Early entrants can deter the entry of later brands if it is profitable to do so. We also assume that firms set prices only after all firms have entered the market, and, therefore, they do not consider any transitory profits.

The equilibrium of the sequential game is the profile of positions $\vec{\theta}^{*}=\left(\theta_{1}^{*}, \theta_{2}^{*}, \ldots\right.$, $\left.\theta_{n}^{*}\right)$ and the vector of prices $\vec{p}^{*}=\left(p_{1}^{*}, p_{2}^{*}, \ldots, p_{n}^{*}\right)$ where

1. $\vec{p}^{*}$ is a Nash equilibrium in prices given product positions $\vec{\theta}^{*}$.

2. Each firm chooses its position rationally taking into consideration the incumbents' positions, predicted future positions, and the ensuing price competition.

3 . Each non-entering firm rationally predicts a loss if it were to enter.

Formally, let $n$ be the last firm to enter. Firm $n$ can observe the positions of the incumbent firms. Let $\vec{\theta}_{-n}=\left(\theta_{1}, \theta_{2}, \ldots, \theta_{n-1}\right)$ be the positions of the earlier entrants. Given $\vec{\theta}_{-n}$, firm $n$ chooses position $\theta_{n}$ so as to maximize:

$$
\Pi_{n}^{f}\left(\vec{\theta} \mid \vec{\theta}_{-n}\right)=\Pi_{n}\left(\vec{p}^{*}(\vec{\theta}), \vec{\theta}\right)
$$

where $\vec{\theta}=\left(\vec{\theta}_{-n}, \theta_{n}\right)$. This maximization problem yields the best possible position for 
firm $n, \theta_{n}^{b}\left(\vec{\theta}_{-n}\right)$, as a function of $\vec{\theta}_{-n}$, the positions of the earlier entrants. Firm $n-1$ maximizes the profit function

$$
\Pi_{n-1}^{f}\left(\vec{\theta} \mid \vec{\theta}_{-(n-1)}\right)=\Pi_{n-1}\left(\vec{p}^{*}(\vec{\theta}), \vec{\theta}_{-n}, \theta_{n}^{b}\left(\vec{\theta}_{-n}\right)\right)
$$

to obtain $\theta_{n-1}^{b}\left(\vec{\theta}_{-(n-1)}\right)$. Notice that in choosing its position, firm $n-1$ anticipates its influence on the position of the last entrant. This influence of $\theta_{n-1}$ on $\theta_{n}$ happens through $\theta_{n}^{b}\left(\vec{\theta}_{-n}\right)$, since $\theta_{n-1}$ is part of $\vec{\theta}_{-n}$. In a similar fashion, firm $i$ in the sequence of entrants selects its best position $\theta_{i}$, conditional on $\vec{\theta}_{-i}$, the profile of product positions of the $i$ -1 earlier entrants and anticipating the influence of its choice on the positions of all later entrants. Finally, the profit for the firm 1 can be written as a function of its position alone, as it anticipates the actions of all future entrants. Given this process, each firm solves for its optimal position, and the set of solutions is the sequential position equilibrium. Firms enter until the next potential entrant makes negative profits. That is, the equilibrium number of firms $n^{*}$ is determined by $\Pi_{n^{*+1}}^{f}(\vec{\theta})<0$ while $\Pi_{n^{*}}^{f}(\vec{\theta}) \geq 0$.

In this section, we discuss the market structure with sequential entry for two unimodal, symmetric preference distributions. Specifically, we analyze the cases when $\alpha=3$ and $\alpha$ $=16$. In the simultaneous positioning game, we found that the nature of the equilibrium in a duopoly depended upon the range of $\alpha$. Therefore, we choose two different levels of heterogeneity, one with $\alpha<11.1$ and the other with $\alpha>11.1$.

\subsection{Fixed Number of Brands}

We first look at the case when the number of brands in the market is fixed exogenously. In this situation, individual firms cannot influence the number of brands in the market. We find that, when the number of brands is predetermined and firms maximize longterm profits, the market structures under sequential entry are identical to those under simultaneous positioning. In a duopoly, for example, the equilibrium positions, prices and profits are the same as those shown in Table 1. When the level of consumer heterogeneity is relatively high (e.g., $\alpha=3$ ), there is no advantage of early entry and both firms earn equal profits. However, when the preference distribution gets more peaked (e.g., $\alpha$ $=16$ ) the first entrant gets a significant advantage by positioning toward the modal preference.

When there are three firms, the equilibrium positions are the same as those shown in Table 2. For both preference distributions, the first firm always locates at the center of the market to take advantage of the concentration of consumers there. Because of its position, the first brand earns higher profits than the two later entrants, both of whom earn equal profits. There are two possible optimal positions for the second firm, one on each side of the first brand. Because of the symmetry in the market it is not possible to predict a priori which of these two positions the second firm will choose. Once the second firm commits to one of its two optimal positions, the third firm takes the other position. Note that the second and third firms have the same market share and earn equal profits. There is, therefore, no special advantage of being the second firm in this market. Only the first firm gets additional profit due to its early entry.

\subsection{Entry Deterrence}

In the previous subsection we saw that, for $\alpha=3$ and when there is no further threat of entry to the duopoly, the equilibrium positions correspond to maximal differentiation. Both firms take up positions at the extreme of the product space, one on each side. At these positions each brand has a profit of $2.582-F$, where $F$ is the fixed cost of entry. We now assume that the number of firms is not predetermined and a new firm will enter if it can find a position that results in a positive profit, after accounting for the fixed cost 
of entry. Would the maximal differentiation positions still be optimal for the first two firms if such a threat of entry was present?

Consider the case when $F=0.1$. With two brands positioned at 0 and 90 degrees respectively, a third firm can enter profitably for this level of fixed cost. The new brand chooses its position at the center and reduces the profits of the earlier brands. In fact, the first two firms are unable to cover their fixed costs anymore. Given the negative consequence of new entry, the first two firms will choose positions so as to deter the entry of the third firm. We now look at such entry deterring behavior.

When firms can deter entry through their strategic actions, they have to be sophisticated in choosing their positions. The greater the number of potential entrants, the more complex is the decision for firms entering early in the sequence. For simplicity, consider a market in which the fixed cost of entry is such that no more than three firms can coexist with non-negative profits. In such a market, after the entry of the pioneer, a second firm enters only if it can cover its fixed cost of entry. If it decides to enter, the second firm then chooses either to deter or accommodate the entry of a third firm after weighing the relative profitability of the two actions. In an analogous manner, the first firm can, for high enough fixed costs, deter the entry of all later firms. In this case, the optimal entry deterring position for the first firm coincides with its monopoly position. Thus, for high fixed costs, further entry is naturally blocked, and the first firm earns monopoly profits. For lower levels of fixed costs, however, the first firm may not have available any position that deters the entry of the second firm. In such a situation, the first firm needs to choose its best position after anticipating the best-response positions of the later firms.

The market structure under free entry, therefore, depends critically on the level of fixed costs. Table 4 shows this relationship for two preference distributions. Consider first the case when consumer preferences are moderately homogeneous $(\alpha=3)$. In this case, at least three firms can profitably enter the market for all fixed cost levels less than 0.015 . The first two firms will be unable to deter the entry of the third firm. The situation changes when fixed costs increase above 0.015 . Here, the early entrants can deter entry of other firms through their positioning choice. When fixed cost is within the range $F$ $\in[0.015,0.18)$, the third firm can be deterred from entering. When fixed costs increase above 0.18 , the first firm can position itself at 45 degrees and deter the entry of the second firm. The pattern of results is similar when $\alpha=16$, although the fixed cost levels at which the switches in market structure occur are different. When fixed costs are less than 0.005 , there are at least three firms in the market. The entry of the third firm is deterred when fixed costs are between 0.005 and 0.025 , resulting in a duopoly. The first entrant can naturally block the entry of all firms when fixed costs are greater than 0.0025 .

The optimal positions with free entry are quite different from the positions firms choose when the number of firms in the market is fixed. Recall that when $\alpha=3$ and there is no threat of entry, duopolists differentiate maximally and position at the ends of the product

TABLE 4

Impact of Fixed Costs on Market Structure

\begin{tabular}{clc}
\hline$\alpha$ & \multicolumn{1}{c}{ Fixed Costs } & Number of Firms \\
\hline \multirow{3}{*}{3} & $0<F<0.015$ & $\geq 3$ \\
& $0.015 \leq F<0.18$ & 2 \\
& $0.18 \leq F$ & 1 \\
\hline \multirow{3}{*}{16} & $0<F<0.005$ & $\geq 3$ \\
& $0.005 \leq F<0.025$ & 2 \\
\hline
\end{tabular}


space. As shown in Figure 8, the equilibrium with free entry is not maximal differentiation. As noted earlier, maximal differentiation by the first two entrants would leave the center of the market open to new entry. To deter entry, the two incumbents move inward and deny the third firm a clear segment of the market. When the level of fixed costs is such that the incumbents can just deter the entry of the third firm, they take on symmetric positions around the modal consumer preference, $\theta_{1}=55$ and $\theta_{2}=35$. None of the three market partitions is large enough to allow a third firm to enter profitably. The inward movement increases price rivalry between the two firms, but any attempt to decrease
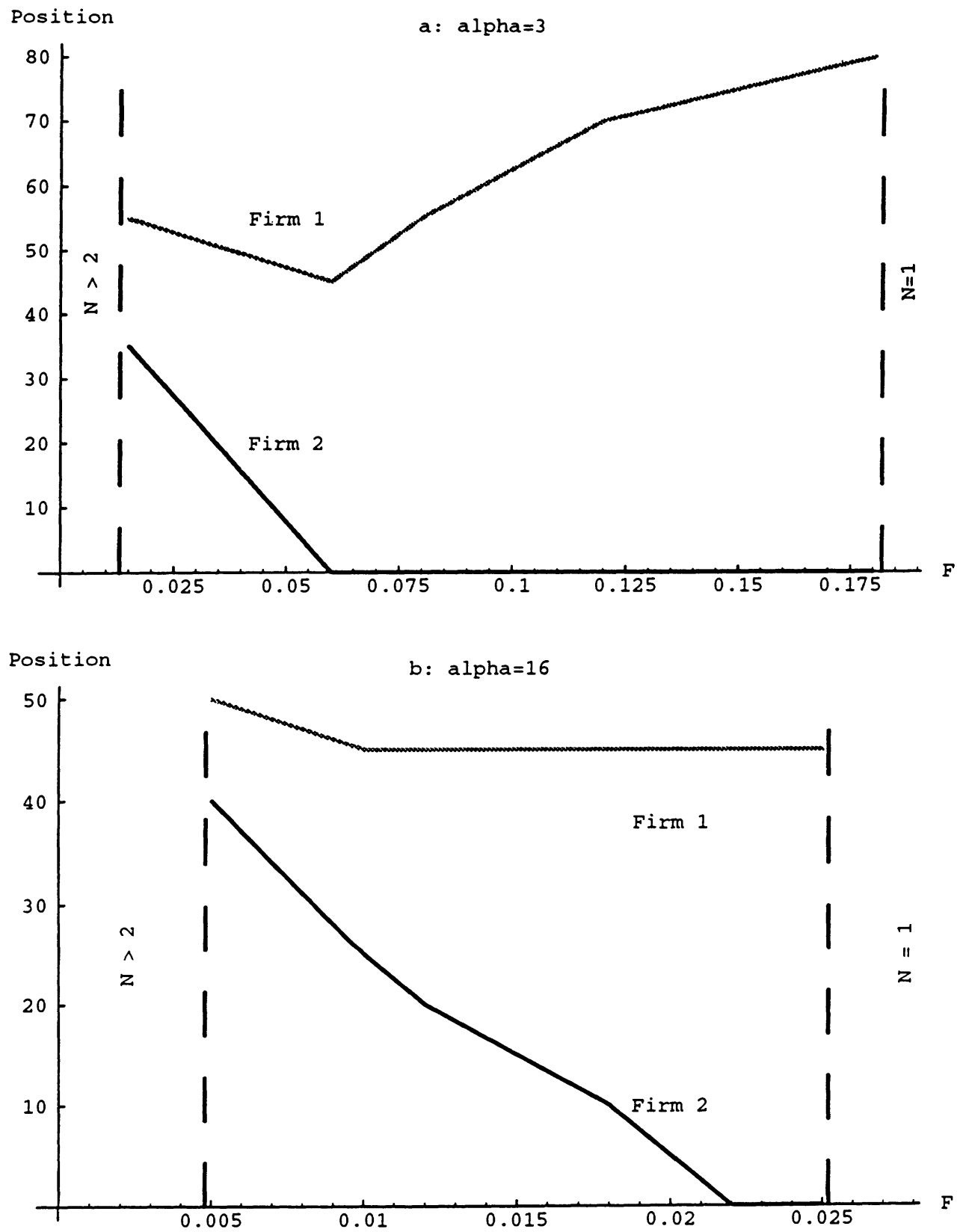

Figure 8. Entry Deterring Positions as a Function of Fixed Costs. 
price competition through differentiation creates the opportunity for the third firm to enter.

The threat of entry by a third firm decreases as $F$ increases. This gives the incumbent firms the opportunity to move away from each other without attracting entry. Since differentiation reduces price rivalry and increases profit, the incumbents move away from each other as much as possible. As shown in Figure 8, differentiation increases monotonically as $F$ increases. There is a particular pattern in which the firms differentiate: Initially the first brand remains close to the modal preference but the second brand moves toward the exterior. This continues until the second brand reaches the end of the market ( 0 degrees). This occurs at $F=0.06$. Once the second brand is at 0 degrees, further increases in $F$ do not affect its position. For fixed costs $F \in(0.06,0.18)$, the best position for the potential entrant lies in the interval $\left[\theta_{2}, \theta_{1}\right)$. However, this position does not yield positive profits.

When fixed costs rise above 0.06 the onus of reducing price competition shifts to the first brand, since the second one cannot move any further. As fixed costs increase within the range $F \in(0.06,0.18)$, the first firm moves away from the center, and the second firm positions at the extreme end, opposite from the position of the first brand. At $F$ $=0.18$, the optimal entry deterring positions of the first and second firms are 80 degrees and 0 degrees respectively. Fixed costs above 0.18 create barriers to entry for the second firm. The first entrant can position itself at 45 degrees, the modal consumer preference, and enjoy monopoly profit.

For $\alpha=16$, and for a fixed number of firms, the equilibrium positions in a duopoly are asymmetric. One firm locates at one extreme corner of the product space and the other takes an internal position on the opposite side. This asymmetric pattern is no longer optimal when there is a threat of entry by a third firm. When the threat of entry is high, i.e., for $F \in(.002,0.005)$, the two incumbents take on internal symmetric positions around the mode of the preference distribution $\left(\theta_{1}=50, \theta_{2}=40\right)$. Because of their symmetric positions, both firms have the same market share, charge the same price, and, therefore, earn the same profit. Thus, the first firm gains no advantage from its early entry. Recall that if the market is a priori fixed to be a duopoly, the first firm to enter gets higher profits than the later entrant. But the threat of entry takes away this advantage.

As the fixed costs increase, the threat of entry reduces, and the behavior of the incumbents changes in a number of ways. Most importantly, the first entrant earns more profit than the second firm for all $F>0.005$. Second, the equilibrium positions are no longer symmetrical. As the fixed cost increases, the first firm moves to the center of the market at the modal preference. The second firm, on the other hand, moves away from the first firm to reduce price competition. Third, contrary to the $\alpha=3$ case, the first firm does not move away from the center once the second firm reaches a market corner. In this case, the greater concentration of customers at the modal position makes this region attractive for the first firm. The first firm retains proximity to these consumers even when it has the opportunity to reduce price competition by moving away. It is for the same reason that one firm takes an internal position in a duopoly without free entry. Finally, when $F>.025$, the first firm can deter the entry of all future entrants. It selects its position at the center of the market and enjoys monopoly power.

\section{Concluding Remarks}

A well-formulated positioning strategy requires a simultaneous analysis of competitor and consumer behavior. In positioning models, the assumptions regarding competitive behavior have become increasingly sophisticated. Yet, the consumer environment in most of these models has remained simplistic. The typical assumption is that consumer 
preferences are uniformly distributed in space. This assumption, it is claimed, provides a uniform backdrop for observing interactions between price competition and market share effects. But, as demonstrated in this paper, it is necessary to examine different markets with varying levels of preference heterogeneity to understand how brand positions are affected by the balance between price competition and market share effects. We use the generalized beta distribution to perform comparative static analyses of positioning strategies with respect to consumer preferences.

We show that the equilibrium positions of brands in competitive markets is significantly affected by the distribution of consumer preferences. Indeed for duopolies and triopolies, we find a variety of equilibrium configurations that are related to the heterogeneity of consumer preferences. Maximal and minimal differentiation are just the two ends of the spectrum of possible configurations. The equilibrium in a particular market reflects the balance between the repelling impact of price competition and the agglomerative influence due to the market share effect.

In markets with uniform preferences, because of high consumer heterogeneity, the impact of price competition on brand positions is extremely strong. The homogenization of consumer preferences gives rise to an agglomerative force that counterbalances the repelling impact of price competition. As consumer preferences become more peaked, this agglomerative force exerts greater influence and brands tend to move inward. Therefore, the optimal positions of brands depend upon the level of heterogeneity in consumer preferences. In the three-brand case, the two exterior brands move inward in a regular fashion as the consumer preference distribution gets more peaked (the interior brand always prefers the modal consumer preference). This interior movement of brands also happens abruptly in some cases. In a duopoly, for example, brands are maximally differentiated when preferences are uniform. However, when preferences are relatively homogeneous, at equilibrium one brand takes an interior position, while the other chooses to be at the extreme of the product space. The change from one type of equilibrium to the other occurs abruptly as the concentration of consumers towards the middle of the market increases continuously. Thus, small changes in the distribution of consumer preferences can have significant effects on the equilibrium positions and prices of brands.

Our results also establish the advantage of early entry when firms enter in a sequence. The extent of this advantage depends upon the nature of consumer preferences. In a duopoly, first entrants have no advantage when consumer preferences are heterogeneous, but the advantage grows as the distribution becomes more peaked. When there are three firms, too, the advantage of the first entrant is larger in markets where consumer preferences are peaked. When consumer preference distributions are relatively homogeneous, positions near the modal preference are highly preferred. In such a scenario, early entry is desirable since the first entrant can capture the most preferred position.

We demonstrate, too, how the threat of potential entry affects the behavior of firms. Early entrants have to sacrifice some of their potential advantage in order to deter entry. The best entry-deterring strategy also depends on the distribution of consumer preferences, along with the level of fixed costs. The relationship between fixed costs and the number of entrants in a market is well known. But we show that the level of fixed cost also affects the equilibrium position of entrants in this market. When fixed costs are low, early entrants position near the modal consumer preference to deter the entry of later entrants. Positioning near each other in this fashion, increases price competition and adversely affects their profits. As fixed costs increase, the threat of entry diminishes, and incumbents can differentiate to reduce price rivalry. The pattern of differentiation depends both on the level of fixed cost and the extent of homogeneity in consumer preferences. Thus the behavior of firms faced with the threat of future entry depends on the consumer, competitive, and cost environments in an intricate fashion. 
The introduction of a more general consumer preference distribution in positioning models adds considerably to their realism. However, the introduction of a more general distribution comes at the price of analytical complexity. We combine analytical calculus, a numerical search procedure and the powers of symbolic algebra software to establish and determine the equilibrium outcomes. We provide a method for proving existence and uniqueness for models in which direct analytical proofs are not possible because of their complexity. While some may have preferred the mathematical elegance of analytical solutions in simple environments, we prefer the empirical richness of the Defender model and add to its realism through our assumption of nonuniform preferences.

Our results provide important insights into positioning strategy. However, a number of aspects of product positioning remain unexplored. For example, extending the current framework to more than two attributes should be worthwhile. It is possible that in such multi-attribute markets firms may differentiate on the some attributes but not on others. Another possible extension is to model dynamic games in which firms choose positions in the first stage, taking into consideration the outcomes from repeated price games. It is likely that cooperative behavior might emerge in such environments and thus influence the positioning decisions of forward looking firms. Finally, future research should look at the behavior of multi-product firms concerned with maximizing profits of an entire product line. ${ }^{11}$

Acknowledgments. The authors thank Tom Pugel, Ambar Rao, Joel Steckel, Larry White and the participants at the Industrial Organization seminar at the Stern School of Business for helpful comments. The paper has also benefitted from suggestions of John Hauser, Anne Coughlan, and two anonymous reviewers.

\footnotetext{
${ }^{11}$ This paper was received August 1, 1992, and has been with the authors 7 months for 2 revisions. This paper was processed by Anne T. Coughlan, Area Editor.
}

Appendix

\section{Demand Expressions}

Here we present the demand expressions, profit functions and the first order conditions for the price subgame. We present these for the three-brand case.

The demand for the firms is given by:

$$
\begin{aligned}
& D_{1}=\int_{0}^{\alpha_{12}} \frac{\Gamma(2 \alpha)\left(90 \theta-\theta^{2}\right)^{(\alpha-1)} d \theta}{\Gamma(\alpha)^{2} 90^{(2 \alpha-1)}} \\
& D_{2}=\int_{\alpha_{12}}^{\alpha_{23}} \frac{\Gamma(2 \alpha)\left(90 \theta-\theta^{2}\right)^{(\alpha-1)} d \theta}{\Gamma(\alpha)^{2} 90^{(2 \alpha-1)}}
\end{aligned}
$$

and

$$
D_{3}=\int_{\alpha_{23}}^{90} \frac{\Gamma(2 \alpha)\left(90 \theta-\theta^{2}\right)^{(\alpha-1)} d \theta}{\Gamma(\alpha)^{2} 90^{(2 \alpha-1)}}
$$

where,

$$
\alpha_{12}=\arctan \left(\frac{p_{2} \cos \theta_{1}-p_{1} \cos \theta_{2}}{p_{1} \sin \theta_{2}-p_{2} \sin \theta_{1}}\right) \quad \text { and } \quad \alpha_{23}=\arctan \left(\frac{p_{3} \cos \theta_{2}-p_{2} \cos \theta_{3}}{p_{2} \sin \theta_{3}-p_{3} \sin \theta_{2}}\right)
$$

The above expressions can be used to arrive at the profit functions for firm $i$. The profit for firm $i$ is given by

$$
\Pi_{i}=\left(p_{i}-c_{i}\right) D_{i}
$$

where we assume that $c_{i}=1$ for each $i$.

The first order conditions for the price equilibria can be derived using Leibnitz rule. The conditions are given below. 


$$
\frac{\partial \Pi_{1}}{\partial p_{1}}=\frac{\Gamma(2 \alpha)}{\Gamma(\alpha)^{2}}\left[\int_{0}^{\alpha_{12} / 90}\left(x-x^{2}\right)^{(\alpha-1)} d x+\left(p_{1}-c_{1}\right)\left\{\frac{\left(90 \alpha_{12}-\alpha_{12}^{2}\right)^{\alpha-1}}{90^{2 \alpha-1}} \frac{\partial \alpha_{12}}{\partial p_{1}}\right\}\right]=0
$$

where

$$
\begin{gathered}
\frac{\partial \alpha_{21}}{\partial p_{1}}=\frac{-p_{2} \sin \left(\theta_{2}-\theta_{1}\right)}{p_{1}^{2}+p_{2}^{2}-2 p_{1} p_{2} \cos \left(\theta_{2}-\theta_{1}\right)} . \\
\frac{\partial \Pi_{2}}{\partial p_{2}}=\frac{\Gamma(2 \alpha)}{\Gamma(\alpha)^{2}}\left[\int_{\alpha_{12} / 90}^{\alpha_{32} / 90}\left(x-x^{2}\right)^{\alpha-1} d x+\left(p_{2}-c_{2}\right)\left\{\frac{\left(90 \alpha_{32}-\alpha_{32}^{2}\right)^{\alpha-1}}{90^{2 \alpha-1}} \frac{\partial \alpha_{32}}{\partial p_{2}}\right.\right. \\
\left.\left.-\frac{\left(90 \alpha_{12}-\alpha_{12}^{2}\right)^{\alpha-1}}{90^{2 \alpha-1}} \frac{\partial \alpha_{12}}{\partial p_{2}}\right\}\right]=0
\end{gathered}
$$

where

$$
\frac{\partial \alpha_{12}}{\partial p_{2}}=\frac{p_{1} \sin \left(\theta_{2}-\theta_{1}\right)}{p_{1}^{2}+p_{2}^{2}-2 p_{1} p_{2} \cos \left(\theta_{2}-\theta_{1}\right)} \quad \text { and } \quad \frac{\partial \alpha_{32}}{\partial p_{2}}=\frac{-p_{3} \sin \left(\theta_{3}-\theta_{2}\right)}{p_{2}^{2}+p_{3}^{2}-2 p_{2} p_{3} \cos \left(\theta_{3}-\theta_{2}\right)}
$$

and finally

$$
\frac{\partial \Pi_{3}}{\partial p_{3}}=\frac{\Gamma(2 \alpha)}{\Gamma(\alpha)^{2}}\left[\int_{\alpha_{32} / 90}^{1}\left(x-x^{2}\right)^{(\alpha-1)} d x+\left(p_{3}-c_{3}\right)\left\{-\frac{\left(90 \alpha_{32}-\alpha_{32}^{2}\right)^{\alpha-1}}{90^{2 \alpha-1}} \frac{\partial \alpha_{32}}{\partial p_{3}}\right\}\right]=0
$$

where

$$
\frac{\partial \alpha_{32}}{\partial p_{3}}=\frac{p_{2} \sin \left(\theta_{3}-\theta_{2}\right)}{p_{3}^{2}+p_{2}^{2}-2 p_{3} p_{2} \cos \left(\theta_{3}-\theta_{2}\right)} .
$$

These first order conditions are non-linear in prices and do not yield closed form expressions for $\vec{p}^{*}$.

\section{Algorithms}

I. The algorithm to check for quasi-concavity of profit function $j$ is as follows:

Step 1: Fix a symmetric unimodal beta distribution by specifying its parameters $\alpha_{1}=\alpha_{2}=\alpha>1$.

Step 2: Fix a high reservation price $R$ above which no consumer buys the good.

Step 3: Loop over $\theta_{1}$ and $\theta_{2}$ with $\theta_{1}$ varying from 0 to 88 degrees in 2 degree increments and $\theta_{2}$ varying from $\theta_{1}+2$ to 90 degrees.

Step 4: Loop over $p_{2}$ from marginal cost $c$ to reservation price $R$ in a grid.

Step 5: For each $\theta_{1}, \theta_{2}, p_{1}, p_{2}$ combination, vary $p_{1}$ from marginal cost $c$ to price $p_{1}^{\max }$ (at which $D_{1}=0$ ) in steps of $\epsilon=\left(p_{1}^{\max }-c\right) / 11$.

Step 6: For each combination of $\theta_{1}, \theta_{2}, p_{1}$ and $p_{2}$ check that the second derivative of $1 / D_{1}$ with respect to $p_{1}$ is positive.

II. Algorithm to check for negative quasi-definiteness of the Jacobian.

Steps 1-5: Identical as in the existence algorithm above.

Step 6: For each combination of $\theta_{1}, \theta_{2}, p_{1}$ and $p_{2}$, check that the Jacobian of the best reply function is quasinegative definite or equivalently that $J^{*} \equiv J+J^{T}$ is negative definite.

III. Algorithm to determine the subgame perfect product and price equilibrium.

Given a pair of positions $\left(\theta_{1}, \theta_{2}\right)$ and parameter $\alpha$ and a specific value for the marginal cost, the system of equations, (6) can be solved numerically through the application of Newton's method. For all results presented in the paper, a marginal cost of one was used.

The procedure for determining equilibrium price is embedded in a vertex substitution algorithm to determine the subgame-perfect equilibrium as follows:

Step 1: Initialize $l=1$.

Step 2: Fix $\theta_{2}$, the position of brand 2, to some initial value $\theta_{2}^{l}$ between 0 and 90 degrees.

Step 3: Vary the position of brand 1 from 0 to $\left(\theta_{2}^{l}-\epsilon\right)$ degrees in increments of $\epsilon$. Calculate the second stage equilibrium prices and profits for each pair of positions. Identify the position for brand 1 that maximizes profit for that brand. Call this $\theta_{1}=\theta_{1}^{l}$.

Step 4: Fix $\theta_{1}$ at $\theta_{1}^{l}$. Vary the position of brand 2 from $\theta_{1}^{l}+\epsilon$ to 90 degrees in increments of $\epsilon$ and calculate the second stage equilibrium prices and profits for each pair of positions. Identify the position for brand 2 that maximizes profit for that brand. Call this $\theta_{2}=\theta_{2}^{(l+1)}$ and fix the position of brand 2 at this point.

Step 5: Increment $l$ by 1 and repeat Steps 3 and 4. Stop if $\theta_{1}^{(l+1)}=\theta_{1}^{l}$ and $\theta_{2}^{(l+1)}=\theta_{2}^{l}$. Otherwise, return to Step 3.

The entire algorithm was programmed in Mathematica. The programs are available from the authors on request. In addition to using multiple initial prices in Steps 3 and 4, we also used multiple starting positions in 
Step 2 to avoid ending in local optima that are not globally optimal. In each case the procedure converged to the same pair of positions.

\section{References}

Archibald, G. C., B. C. Eaton and R. G. Lipsey (1986), “Address Models of Value Theory," in J. E. Stiglitz and G. F. Mathewson (Eds.), New Developments in the Analysis of Market Structure, Cambridge, MA: MIT Press.

D’Aspremont, C., J. J. Gabszewicz and J.-F. Thisse (1979), "On Hotelling's Stability in Competition," Econometrica, 47, 1145-1150.

Caplin, A. and B. Nalebuff (1991), "Aggregation and Imperfect Competition: On the Existence of Equilibrium," Econometrica, 59, 25-59.

Carpenter, G. S. (1989), "Perceptual Position and Competitive Brand Strategy in a Two-Dimensional, TwoBrand Market," Management Science, 35, 1029-1044.

Debreu, G. (1952), “A Social Equilibrium Existence Theorem," Proceedings of the National Academy of Sciences, $38,886-893$.

Eaton, B. C. and R. G. Lipsey (1975), "The Principle of Minimum Differentiation Reconsidered: Some New Developments in the Theory of Spatial Competition," Review of Economic Studies, 42, 27-49.

Economides, N. (1984), "The Principle of Minimum Differentiation Revisited," European Economic Review, 24, 345-368.

- (1986a), "Nash Equilibrium Existence in Duopoly with Products Defined by Two Characteristics," Rand Journal of Economics, 17, 431-439.

(1986b), "Minimal and Maximal Product Differentiation in Hotelling's Duopoly," Economics Letters, $21,67-71$.

_ (1989), "Symmetric Equilibrium Existence and Optimality in Differentiated Products Markets," Journal of Economic Theory, 47, 178-194.

Ehrenberg, A. S. C. (1959), "The Pattern of Consumer Purchases," Applied Statistics, 8, 26-41.

- (1972), Repeat Buying, Amsterdam: North Holland.

Friedman, J. W. (1986), Game Theory with Applications to Economics, Oxford: Oxford University Press.

Gale, D. and H. Nikaido (1965), "The Jacobian Matrix and the Global Univalence of Mappings," Mathematische Annalen, 159, 81-93.

Hauser, J. and M. Shugan (1983), "Defensive Marketing Strategy," Marketing Science, 2, 319-360. (1988), "Competitive Price and Positioning Strategies," Marketing Science, 7, 76-91.

and B. Wernerfelt (1988), "Existence and Uniqueness of Price Equilibria in Defender," Marketing Science, 7, 92-93.

Hotelling, H. (1929), "Stability in Competition," Economic Journal, 39, 41-57.

Kotler, P. ( 1990), Marketing Management, Englewood Cliffs, NJ: Prentice Hall.

Kumar, R. V. and D. Sudarshan (1988), "Defensive Marketing Strategies: An Equilibrium Analysis Based on Decoupled Response Function Models," Management Science, 34, 805-815.

Lancaster, K. (1990), "The Economics of Product Variety," Marketing Science, 9, 189-206.

Lane, W. J. ( 1980 ), "Product Differentiation in a Market with Endogenous Sequential Entry," The Bell Journal of Economics, 11, 237-260.

Moorthy, S. K. ( 1988 ), "Product and Price Competition in a Duopoly," Marketing Science, 5, 141-168.

Nash, J. ( 1951 ), “Non-cooperative Games," Annals of Mathematics, 45, 286-295.

Neven, D. (1986), "On Hotelling's Competition with Non-Uniform Customer Distribution," Economics Letters, 21, 121-126.

Prescott, E. C. and M. Visscher (1977), "Sequential Locations Among Firms with Foresight," The Bell Journal of Economics, 8, 378-393.

Rosen, J. B. (1965), "Existence and Uniqueness of Equilibrium Points for Concave $N$-Person Games," Econometrica, 33, 520-534.

Shaked, A. and J. Sutton (1982), "Relaxing Price Competition Through Product Differentiation," Review of Economic Studies, 49, 3-13.

Shapiro, B. P., R. J. Dolan and J. A. Quelch (1985), Marketing Management, I, Homewood, Illinois: Irwin.

Shugan, S. M. (1987), "Estimating Brand Positioning Maps Using Supermarket Scanning Data," Journal of Marketing Research, 24 (February), 1-18.

Urban, G. L. and Hauser, J. R. (1980), Design and Marketing of New Products, Englewood Cliffs, NJ: Prentice Hall.

Waarts, E., M. Carree and B. Wierenga ( 1991), "Full-Information Maximum Likelihood Estimation of Brand Positioning Maps Using Supermarket Scanning Data," Journal of Marketing Research, 28, 483-490.

Wind, Y. (1990), "Positioning Analysis and Strategy," in George Day, Barton Weitz and Robin Wensley (Eds.), The Interface of Marketing and Strategy, Greenwich, Connecticut: JAI Press. 